\title{
Luminescent Carbazole-Based EuIII and YbIII Complexes with High Two-Photon Absorption Cross-Section Enable Viscosity-Sensing in the Visible and Near IR with One- and Two-Photon Excitation
}

\author{
Jorge H.S.K. Monteiro, Natalie R. Fetto, Matthew J. Tucker, Ana de Bettencourt-Dias* \\ Department of Chemistry, University of Nevada, Reno, NV 89557.
}

\section{Table of Contents}

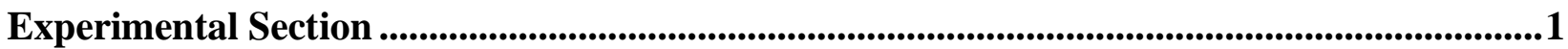

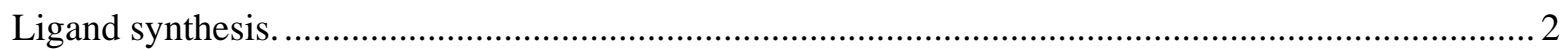

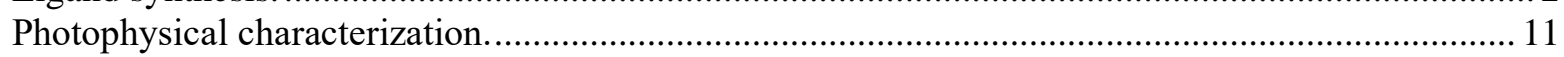

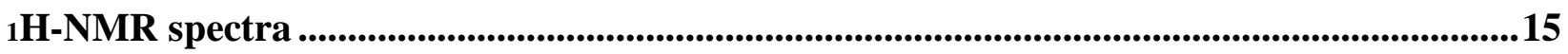

13C-NMR

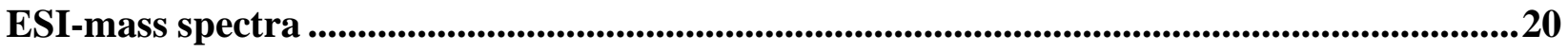

Photophysical characterization ......................................................................................................23

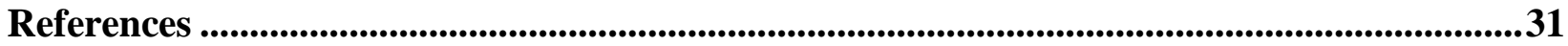

\section{Experimental Section}

All commercially obtained reagents were of analytical grade and used as received. Solvents were dried by standard methods. The stock solutions of europium(III) and ytterbium(III) chloride were prepared by dissolving the chloride salts in water. The concentration of the metal was determined by complexometric titration with EDTA $(0.01 \mathrm{M})$ using xylenol orange as indicator.1 
Ligand synthesis. The ligands $\mathrm{H}_{2} \mathrm{CPAD}$ and $\mathrm{H}_{4} \mathrm{CPAP}$ were synthesized using modified literature procedures,2-11 as shown in Scheme S1.
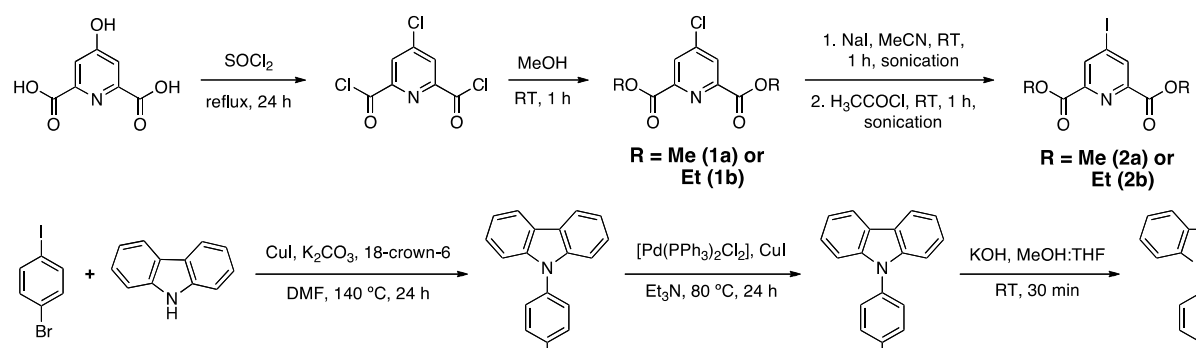

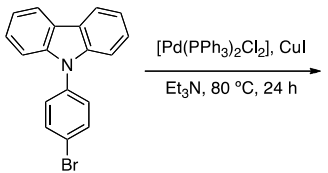

(3)

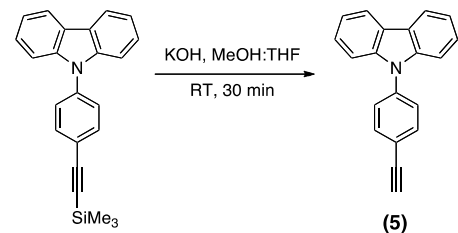

(4)

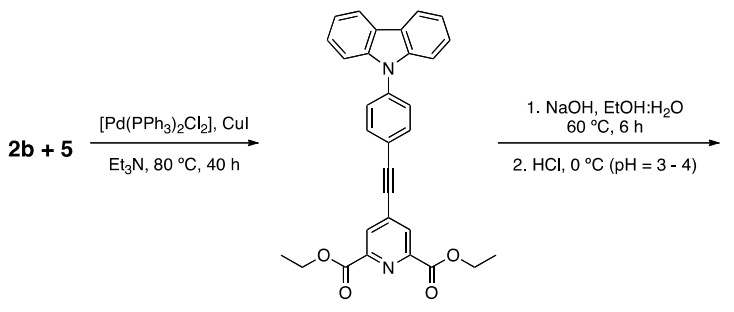

(6)

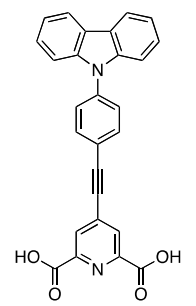

( $\left.\mathrm{H}_{2} \mathrm{CPAD}\right)$

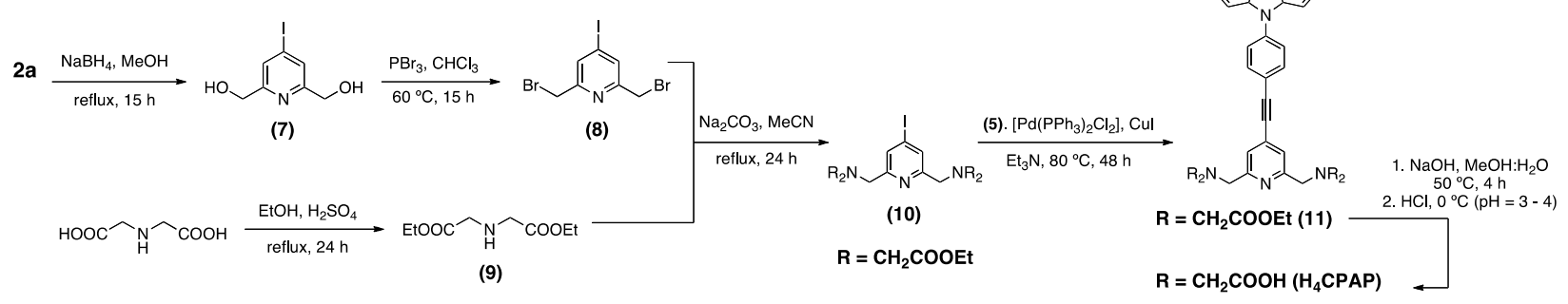

Scheme S1. Synthesis of $\mathrm{H}_{2} \mathrm{CPAD}$ and $\mathrm{H}_{4} \mathrm{CPAP}$.

Synthesis of dimethyl 4-chloropyridine-2,6-dicarboxylate (1a).11 $3.0 \mathrm{~g}(16.4 \mathrm{mmol})$ chelidamic acid monohydrate was added to $10 \mathrm{~mL} \mathrm{SOCl} 2$ with $1 \mathrm{~mL}$ of DMF. The white suspension was refluxed for $24 \mathrm{~h}$ to yield a green-yellow solution. The $\mathrm{SOCl}_{2}$ was removed under reduced pressure, $12 \mathrm{~mL}$ methanol was added under cooling, and the system was stirred for $1 \mathrm{~h}$ at RT. The excess methanol was removed under reduced pressure, the residue dissolved in dichloromethane and washed with water $(2 \mathrm{x})$ and brine (2x). The organic phases were combined, dried over $\mathrm{Na}_{2} \mathrm{SO}_{4}$, filtered and the solvent removed under reduced pressure to yield $3.08 \mathrm{~g}(82 \%)$ of a white solid. 
${ }_{1} \mathrm{H}-\mathrm{NMR}\left(\mathrm{CDCl}_{3}, 400 \mathrm{MHz}\right): 8.30$ (s, 2H, py); 4.04 (s, 6H, CH3) ppm.

${ }_{13} \mathrm{C}\{1 \mathrm{H}\}-\mathrm{NMR}\left(\mathrm{CDCl}_{3}, 100 \mathrm{MHz}\right): 164.1 ; 149.4 ; 146.8 ; 128.3 ; 53.5 \mathrm{ppm}$.

ESI-MS found (calc): $[\mathrm{M}+\mathrm{H}]+230$ (230).

Synthesis of diethyl 4-chloropyridine-2,6-dicarboxylate (1b).11 Synthesized as 1a using $3 \mathrm{~g}$ (16.4 mmol) of chelidamic acid monohydrate and $10 \mathrm{~mL}$ of SOCl2. Yield: $3.21 \mathrm{~g} \mathrm{(76 \% ).}$

1H-NMR (CDCl $3,500 \mathrm{MHz}): 8.26$ (s, 2H, py); 4.50 (q, $\left.\mathrm{CH}_{2}, J=7.1 \mathrm{~Hz}, 4 \mathrm{H}\right), 1.46$ (t, $\mathrm{CH}_{3}, J=$ $7.1 \mathrm{~Hz}, 6 \mathrm{H}) \mathrm{ppm}$.

${ }_{13 \mathrm{C}}\left\{{ }_{1} \mathrm{H}\right\}-\mathrm{NMR}\left(\mathrm{CDCl}_{3}, 125 \mathrm{MHz}\right): 163.7 ; 149.9 ; 146.6 ; 128.1 ; 62.7 ; 14.2 \mathrm{ppm}$.

ESI-MS found (calc): $[\mathrm{M}+\mathrm{H}]+258$ (258).

Synthesis of dimethyl 4-iodopyridine-2,6-dicarboxylate (2a).4 $600 \mathrm{mg}$ (2.34 mmol) of 1a was dissolved in $10 \mathrm{~mL}$ of acetonitrile, and $3.49 \mathrm{~g}(23.3 \mathrm{mmol}) \mathrm{NaI}$ added to yield a yellow suspension. The system was sonicated for $1 \mathrm{~h}$ at RT, followed by dropwise addition of $0.5 \mathrm{~mL}$ of acetyl chloride. After sonication for an additional $1 \mathrm{~h}$ at $\mathrm{RT}$ the reaction was quenched with $\mathrm{NaHCO}_{3}$ until $\mathrm{pH} \sim 7$ and diluted with $\mathrm{CH}_{2} \mathrm{Cl}_{2}$. The organic phase was washed with $\mathrm{Na}_{2} \mathrm{~S}_{2} \mathrm{O}_{3}(2 \mathrm{x})$, water $(2 \mathrm{x})$ and brine (2x). The organic phase was dried over $\mathrm{Na}_{2} \mathrm{SO}_{4}$, filtered and the solvent removed under reduced pressure to yield a pale yellow solid. Yield: $650 \mathrm{mg}(80 \%)$.

${ }_{1} \mathrm{H}-\mathrm{NMR}\left(\mathrm{CDCl}_{3}, 400 \mathrm{MHz}\right): 8.67$ (s, py, 2H), 4.03 (s, CH3, 6H) ppm.

${ }_{13 \mathrm{C}}\left\{{ }_{1} \mathrm{H}\right\}-\mathrm{NMR}\left(\mathrm{CDCl}_{3}, 100 \mathrm{MHz}\right): 163.8,148.3,137.1,107.0,53.4 \mathrm{ppm}$.

ESI-MS found (calc): $[\mathrm{M}+\mathrm{H}]+322$ (322). 
Synthesis of diethyl 4-iodopyridine-2,6-dicarboxylate (2b).4 Synthesized using the same procedure as described for $\mathbf{2 a}$, using $600 \mathrm{mg}(2.33 \mathrm{mmol})$ of $\mathbf{1 b}$ and $3.49 \mathrm{~g}(23.3 \mathrm{mmol})$ of NaI. Yield: 610 $\operatorname{mg}(75 \%)$.

1H-NMR ( $\left.\mathrm{CDCl}_{3}, 400 \mathrm{MHz}\right): 8.64$ (s, py, 2H), 4.59 (q, $\left.\mathrm{CH}_{2}, J=7.1 \mathrm{~Hz}, 4 \mathrm{H}\right), 1.45$ (t, $\mathrm{CH}_{3}, J=7.1$ $\mathrm{Hz}, 6 \mathrm{H}) \mathrm{ppm}$.

${ }_{13} \mathrm{C}\{1 \mathrm{H}\}-\mathrm{NMR}\left(\mathrm{CDCl}_{3}, 100 \mathrm{MHz}\right): 163.4,148.8,136.9,106.8,62.7,14.2 \mathrm{ppm}$

ESI-MS found (calc): $[\mathrm{M}+\mathrm{H}]+350$ (350).

Synthesis of 9-(4-bromophenyl)-9H-carbazole (3).9 $150 \mathrm{mg}(0.9 \mathrm{mmol})$ carbazole and $186.6 \mathrm{mg}$ (1.35 mmol) $\mathrm{K}_{2} \mathrm{CO}_{3}$ were suspended in $5 \mathrm{~mL}$ of DMF. To this suspension, $9 \mathrm{mg}(0.045 \mathrm{mmol}) \mathrm{CuI}$, $12 \mathrm{mg}$ (0.045 mmol) 18-crown-6 and $458.3 \mathrm{mg}$ (162 mmol) 4-bromo-1-iodobenzene were added and kept under stirring for $24 \mathrm{~h}$ at $120^{\circ} \mathrm{C}$ to yield a bright yellow suspension. The suspension was diluted with $\mathrm{CH}_{2} \mathrm{Cl}_{2}$ and washed with brine (3x). The organic phase was dried over $\mathrm{Na}_{2} \mathrm{SO}_{4}$, filtered and the solvent removed under reduced pressure. The product was purified using silica column and petroleum ether as eluent $\left(R_{f} \sim 0.15\right)$ and was isolated as a white crystalline solid. Yield: $164 \mathrm{mg}$ $(57 \%)$.

1H-NMR ( $\left.\mathrm{CDCl}_{3}, 500 \mathrm{MHz}\right): 8.14(\mathrm{~d}, \mathrm{CH}, J=7.4 \mathrm{~Hz}, 2 \mathrm{H}), 7.73(\mathrm{~d}, \mathrm{CH}, J=8.7 \mathrm{~Hz}, 2 \mathrm{H}), 7.46(\mathrm{~d}$, $\mathrm{CH}, J=8.7 \mathrm{~Hz}, 2 \mathrm{H}), 7.41-7.36(\mathrm{~m}, \mathrm{CH}, 4 \mathrm{H}), 7.30$ (m, CH, 2H) ppm.

${ }_{13} \mathrm{C}\{1 \mathrm{H}\}-\mathrm{NMR}\left(\mathrm{CDCl}_{3}, 125 \mathrm{MHz}\right): 140.6,136.8,133.1,128.7,126.1,123.5,120.9,120.4,120.2$, $109.5 \mathrm{ppm}$.

ESI-MS found (calc): $[\mathrm{M}+\mathrm{H}]+323$ (322). 
Synthesis of 9-(4-((trimethylsilyl)ethynyl)phenyl)-9H-carbazole (4).10 $150 \mathrm{mg}(0.47 \mathrm{mmol})$ of $\mathbf{3}, 17$ $\mathrm{mg}(0.23 \mathrm{mmol})\left[\mathrm{Pd}\left(\mathrm{PPh}_{3}\right)_{2} \mathrm{Cl}_{2}\right]$ and $8 \mathrm{mg}(0.044 \mathrm{mmol}) \mathrm{CuI}$ were suspended in $8 \mathrm{~mL}$ of dry Et3 $\mathrm{N}$. $0.2 \mathrm{~mL}(1.4 \mathrm{mmol})$ of trimethylsilylacetylene was added and the system was kept under stirring for 30 min at RT. After that, the temperature was raised to $80{ }^{\circ} \mathrm{C}$ and stirred for $24 \mathrm{~h}$. After cooling down to RT, the suspension was filtered through a celite pad and the solvent removed under reduced pressure. The product was purified using silica column and petroleum ether as eluent $\left(R_{f}\right.$ $\sim 0.25)$ and isolated as a white solid. Yield: $73 \mathrm{mg}(50 \%)$.

1H-NMR (CDCl $3,500 \mathrm{MHz}): 8.14(\mathrm{~d}, \mathrm{Cbz}, J=7.7 \mathrm{~Hz}, 2 \mathrm{H}), 7.70(\mathrm{~d}, \mathrm{Ph}, J=8.6 \mathrm{~Hz}, 2 \mathrm{H}), 7.52$ (d, $\mathrm{Ph}, J=8.6 \mathrm{~Hz}, 2 \mathrm{H}), 7.41(\mathrm{~m}, \mathrm{Cbz}, 4 \mathrm{H}), 7.29$ (ddd, $\mathrm{Cbz}, J=8.0,5.6$ and $2.5 \mathrm{~Hz}, 2 \mathrm{H}), 0.30\left(\mathrm{~s}, \mathrm{CH}_{3}\right.$, 9H) ppm.

${ }_{13} \mathrm{C}\{1 \mathrm{H}\}-\mathrm{NMR}\left(\mathrm{CDCl}_{3}, 125 \mathrm{MHz}\right): 140.5,137.8,133.5,126.7,126.0,123.6,122.1,120.4,120.2$, 109.7, 104.3, 95.4, $-0.03 \mathrm{ppm}$.

ESI-MS found (calc): $[\mathrm{M}+\mathrm{H}]+340$ (340).

Synthesis of 9-(4-ethynylphenyl)-9H-carbazole (5).10 $73 \mathrm{mg}(0.22 \mathrm{mmol})$ of 4 was dissolved in 3 $\mathrm{mL}$ of MeOH:THF (1:1, v/v) under $\mathrm{N}_{2}$ atmosphere. $14 \mathrm{mg}(0.25 \mathrm{mmol}) \mathrm{KOH}$ dissolved in $1 \mathrm{~mL}$ of water was added. The reaction was kept under stirring for $30 \mathrm{~min}$ at RT. The organic solvents were removed under reduced pressure, followed by dilution with $\mathrm{CH}_{2} \mathrm{Cl}_{2}$. The organic phase was washed with water (2x), dried over $\mathrm{Na}_{2} \mathrm{SO}_{4}$, filtered and the solvent removed under high vacuum to yield a white solid in quantitative yield that was kept under $\mathrm{N}_{2}$ and used immediately. ${ }_{1} \mathrm{H}-\mathrm{NMR}\left(\mathrm{CDCl}_{3}, 500 \mathrm{MHz}\right): 8.14(\mathrm{dd}, \mathrm{Cbz}, J=7.7$ and $1.0 \mathrm{~Hz}, 2 \mathrm{H}), 7.73(\mathrm{~d}, \mathrm{Ph}, J=8.6 \mathrm{~Hz}, 2 \mathrm{H})$, $7.55(\mathrm{~d}, \mathrm{Ph}, J=8.7 \mathrm{~Hz}, 2 \mathrm{H}), 7.42(\mathrm{~m}, \mathrm{Cbz}, 4 \mathrm{H}), 7.30$ (ddd, $\mathrm{Cbz}, J=8.1,4.6$ and $3.6 \mathrm{~Hz}, 2 \mathrm{H}), 3.18$ (s, $\mathrm{CH}, 1 \mathrm{H}) \mathrm{ppm}$. 
${ }_{13} \mathrm{C}\{1 \mathrm{H}\}-\mathrm{NMR}\left(\mathrm{CDCl}_{3}, 125 \mathrm{MHz}\right): 140.5,138.1,133.8,126.8,125.7,123.6,121.1,120.5,120.3$, $110.1,82.9$ ppm.

ESI-MS found (calc): $[\mathrm{M}+\mathrm{H}]+268$ (268).

Synthesis of diethyl 4-((4-(9H-carbazol-9-yl)phenyl)ethynyl)pyridine-2,6-dicarboxylate (6). $66 \mathrm{mg}$ $(0.19 \mathrm{mmol})$ of 2 was dissolved in $3 \mathrm{~mL}$ of dry Et $3 \mathrm{~N}$, followed by the addition of $11 \mathrm{mg}(0.02$ mmol) $\left[\mathrm{Pd}\left(\mathrm{PPh}_{3}\right)_{2} \mathrm{Cl}_{2}\right]$ and $8 \mathrm{mg} \mathrm{CuI.} \mathrm{In} \mathrm{a} \mathrm{second} \mathrm{flask} 50 \mathrm{mg}(0.19 \mathrm{mmol})$ of 5 was dissolved in 3 $\mathrm{mL}$ of dry Et $3 \mathrm{~N}$, under $\mathrm{N}_{2}$, and added to the reaction. The system was kept under stirring for $40 \mathrm{~h}$ at $80{ }^{\circ} \mathrm{C}$ to yield a yellow suspension. The suspension was diluted with $\mathrm{CH}_{2} \mathrm{Cl}_{2}$ and filtered through a celite pad. The solvent was removed under reduced pressure and the product was purified using silica column, and Hex:EtOAc (2:1) $\left(R_{f} \sim 0.25\right.$ - blue luminescent spot under long UV) as eluent, to yield a yellow solid. Yield: $60 \mathrm{mg}(65 \%)$.

1H-NMR (CDCl3, $400 \mathrm{MHz}): 8.38(\mathrm{~s}, \mathrm{py}, 2 \mathrm{H}), 8.15(\mathrm{~d}, \mathrm{CH}(\mathrm{Cbz}), J=7.8 \mathrm{~Hz}, 2 \mathrm{H}), 7.82(\mathrm{~d}$, $\mathrm{CH}(\mathrm{Cbz}), J=8.3 \mathrm{~Hz}, 2 \mathrm{H}), 7.65(\mathrm{~d}, \mathrm{CH}, J=8.4 \mathrm{~Hz}, 2 \mathrm{H}), 7.47-7.41(\mathrm{~m}, \mathrm{CH}, 4 \mathrm{H}), 7.32$ (ddd, $\mathrm{CH}(\mathrm{Cbz}), J=8.1,6.9,1.4 \mathrm{~Hz}, 2 \mathrm{H}) \mathrm{ppm}$ (Figure S1).

${ }_{13} \mathrm{C}\{1 \mathrm{H}\}$-NMR (CDCl $\left.3,100 \mathrm{MHz}\right): 164.3,149.0,140.3,139.1,134.0,133.7,129.5,126.9,126.2$, 123.7, 120.5, 120.4, 120.2, 109.7, 95.8, 86.3, 62.5, 14.3 ppm (Figure S5).

ESI-MS found (calc): $[\mathrm{M}+\mathrm{H}]+490$ (489).

Synthesis of 4-((4-(9H-carbazol-9-yl)phenyl)ethynyl)pyridine-2,6-dicarboxylic acid (H2CPAD). $35 \mathrm{mg}(0.07 \mathrm{mmol})$ of $\mathbf{6}$ was suspended in $3 \mathrm{~mL}$ of EtOH followed by the addition of $7.2 \mathrm{mg}(0.18$ mmol) $\mathrm{NaOH}$ dissolved in $1 \mathrm{~mL}$ of water. The suspension was kept under stirring for $6 \mathrm{~h}$ at $70^{\circ} \mathrm{C}$. 
The $\mathrm{pH}$ of the reaction was adjusted by the addition of aqueous $\mathrm{HCl}(1 \mathrm{~mol} \mathrm{~L}-1)$ until $\mathrm{pH} \sim 3$, to yield a bright yellow precipitate that was filtered and washed with water. Yield: $74 \%$.

1H-NMR (DMSO-d6, $500 \mathrm{MHz}): 8.51(\mathrm{~s}, \mathrm{py}, 2 \mathrm{H}), 8.27(\mathrm{~d}, \mathrm{Cbz}, J=7.7 \mathrm{~Hz}, 2 \mathrm{H}), 7.98(\mathrm{~d}, \mathrm{Ph}, J=$ $8.6 \mathrm{~Hz}, 2 \mathrm{H}), 7.82(\mathrm{~d}, \mathrm{Ph}, J=8.6 \mathrm{~Hz}, 2 \mathrm{H}), 7.48(\mathrm{~m}, \mathrm{Cbz}, 4 \mathrm{H}), 7.47$ (t, Cbz, 2H), 7.32 (t, Cbz, J= $7.9 \mathrm{~Hz}, 2 \mathrm{H}) \mathrm{ppm}$.

13C-NMR (DMSO-do, 125 MHz): 165.0, 149.1, 139.6, 138.3, 133.9, 132.9, 128.6, 126.9, 126.4, 123.0, 120.6, 119.6, 109.7, 95.1, 86.4 ppm.

ESI-MS found (calc): $[\mathrm{M}+\mathrm{H}]+433$ (433).

Synthesis of (4-iodopyridine-2,6-diyl)dimethanol (7).2-3 $60 \mathrm{mg}(1.58 \mathrm{mmol}) \mathrm{NaBH}_{4}$ was added over $30 \mathrm{~min}$ at $0{ }^{\circ} \mathrm{C}$ to $122 \mathrm{mg}(0.35 \mathrm{mmol})$ of 2 dissolved in $7 \mathrm{~mL}$ of dry ethanol. The solution was kept under stirring at RT for $2 \mathrm{~h}$ and then under reflux for $15 \mathrm{~h}$. The white suspension was cooled to RT, $20 \mathrm{~mL}$ of acetone was added and the solution stirred for $30 \mathrm{~min}$. After the solvent was removed under reduced pressure, $5 \mathrm{~mL}$ of saturated aqueous $\mathrm{NaHCO}_{3}$ was added and the system was kept under stirring at reflux for $1 \mathrm{~h} .5 \mathrm{~mL}$ of water was added and the product extracted with EtOAc $(5 x)$. The organic phases were combined, washed with brine $(2 \mathrm{x})$, dried over $\mathrm{Na}_{2} \mathrm{SO}_{4}$, filtered and the solvent removed under reduced pressure to yield $52 \mathrm{mg}(56 \%)$ of a white solid.

1H-NMR (DMSO-d6, $400 \mathrm{MHz}): 7.70$ (s, py, 2H), 5.48 (t, OH, $J=5.9 \mathrm{~Hz}, 2 \mathrm{H}), 4.48(\mathrm{~d}, \mathrm{CH} 2, J=$ $5.9 \mathrm{~Hz}, 4 \mathrm{H}) \mathrm{ppm}$.

${ }_{13 \mathrm{C}}\{1 \mathrm{H}\}-\mathrm{NMR}$ (DMSO- $\left.d 6,100 \mathrm{MHz}\right): 162.1,126.9,107.4,63.4 \mathrm{ppm}$.

ESI-MS found (calc): [M + H]+ 266 (266). 
Synthesis of 2,6-bis(bromomethyl)-4-iodopyridine (8).2 0.21 mL (2.3 mmol) PBr3 was slowly added to a suspension of $300 \mathrm{mg}$ ( $1.13 \mathrm{mmol})$ of $\mathbf{3}$ in $8 \mathrm{~mL}$ of dry chloroform. The suspension was kept under stirring and reflux for $15 \mathrm{~h}$. After cooling down to RT the $\mathrm{pH}$ was adjusted to 7 with $\mathrm{NaHCO}_{3}(\mathrm{aq})$ and the product extracted with chloroform $(6 \times 20 \mathrm{~mL})$. The organic phase was dried over $\mathrm{Na}_{2} \mathrm{SO}_{4}$, filtered and the solvent removed under reduced pressure to yield a white solid in $75 \%$ yield (332 mg).

1H-NMR (CDCl3, $400 \mathrm{MHz}): 7.75$ (s, py, 2H), 4.45 (s, $\left.\mathrm{CH}_{2}, 4 \mathrm{H}\right)$ ppm.

${ }_{13} \mathrm{C}\{1 \mathrm{H}\}-\mathrm{NMR}\left(\mathrm{CDCl}_{3}, 100 \mathrm{MHz}\right): 157.3,131.9,106.7,32.2 \mathrm{ppm}$.

ESI-MS found (calc): [M + H]+ 392 (392).

Synthesis of diethyl 2,2'-azanediyldiacetate (9).5 $1 \mathrm{~g}(7.5 \mathrm{mmol})$ iminodiacetic acid was suspended in $7 \mathrm{~mL}$ of dry ethanol, and $0.5 \mathrm{~mL}$ of sulfuric acid was added. The suspension was kept under stirring and reflux for $24 \mathrm{~h}$ to yield a transparent solution. The solvent was removed under reduced pressure and the $\mathrm{pH}$ was adjusted to $\sim 6-7$ by the addition of $\mathrm{NaHCO}_{3}(\mathrm{aq})$. The product was extracted with EtOAc (4x), washed with water, brine, dried over $\mathrm{Na}_{2} \mathrm{SO}_{4}$, filtered and the solvent removed under reduced pressure to yield a light yellow oil in $77 \%$ yield $(1.09 \mathrm{~g})$.

1H-NMR ( $\left.\mathrm{CDCl}_{3}, 400 \mathrm{MHz}\right): 4.20$ (q, $\left.\mathrm{OCH}_{2}, J=7.1 \mathrm{~Hz}, 4 \mathrm{H}\right), 3.46\left(\mathrm{~s}, \mathrm{CH}_{2}, 4 \mathrm{H}\right), 2.07$ (s, NH, 1H), $1.28\left(\mathrm{t}, \mathrm{CH}_{3}, J=7.1 \mathrm{~Hz}, 6 \mathrm{H}\right) \mathrm{ppm}$.

${ }_{13 \mathrm{C}}\{1 \mathrm{H}\}-\mathrm{NMR}\left(\mathrm{CDCl}_{3}, 100 \mathrm{MHz}\right): 171.7,60.9,50.2,14.2 \mathrm{ppm}$.

ESI-MS found (calc): $[\mathrm{M}+\mathrm{H}]+190$ (190).

Synthesis of tetraethyl 2,2',2",2"'-(4-iodopyridine-2,6-diyl)bis(methylene)bis(azanetriyl)tetraacetate (10).6 $130 \mathrm{mg}(0.33 \mathrm{mmol})$ of $\mathbf{8}, 125 \mathrm{mg}(0.66 \mathrm{mmol})$ of $\mathbf{9}$ and $700 \mathrm{mg}(6.6 \mathrm{mmol})$ 
$\mathrm{Na}_{2} \mathrm{CO}_{3}$ were suspended in $5 \mathrm{~mL}$ of acetonitrile and kept under stirring for $24 \mathrm{~h}$ at $60{ }^{\circ} \mathrm{C}$. The suspension was filtered and the solvent removed under reduced pressure. The product was purified using silica column and EtOAc $(100 \%)$ as eluent $\left(R_{f} \sim 0.62\right)$ and isolated as yellow oil. Yield: 141 $\operatorname{mg}(70 \%)$.

1H-NMR (CDCl3, $400 \mathrm{MHz}): 7.91$ (s, py, 2H), 4.17 (q, $\left.\mathrm{OCH}_{2}, J=7.2 \mathrm{~Hz}, 8 \mathrm{H}\right), 3.98$ (s, pyCH2, 4H), 3.59 (s, $\left.\mathrm{NCH}_{2}, 8 \mathrm{H}\right), 1.27\left(\mathrm{t}, \mathrm{CH}_{3}, J=7.2 \mathrm{~Hz}, 12 \mathrm{H}\right) \mathrm{ppm}$.

${ }_{13} \mathrm{C}\left\{{ }_{1} \mathrm{H}\right\}-\mathrm{NMR}\left(\mathrm{CDCl}_{3}, 100 \mathrm{MHz}\right): 171.0,159.4,130.5,107.4,60.6,59.4,55.0,14.3 \mathrm{ppm}$.

ESI-MS found (calc): [M + H]+ 608 (608).

Synthesis of tetraethyl 2,2',2",2"'-(4-((4-(9H-carbazol-9-yl)phenyl)ethynyl)pyridine-2,6diyl)bis(methylene)bis(azanetriyl)tetraacetate (11). $50 \mathrm{mg}(0.085 \mathrm{mmol})$ of 6 was dissolved in 2 $\mathrm{mL}$ of dry $\mathrm{Et} 3 \mathrm{~N}$, and $6 \mathrm{mg}(0.01 \mathrm{mmol})\left[\mathrm{Pd}\left(\mathrm{PPh}_{3}\right)_{2} \mathrm{Cl}_{2}\right]$ and $4 \mathrm{mg} \mathrm{CuI} \mathrm{were} \mathrm{added.} \mathrm{In} \mathrm{a} \mathrm{second} \mathrm{flask}$ $22 \mathrm{mg}(0.19 \mathrm{mmol})$ of 9 was dissolved in $3 \mathrm{~mL}$ of dry Et3 $\mathrm{N}$, under $\mathrm{N}_{2}$, and added to the reaction. The system was kept under stirring for $40 \mathrm{~h}$ at $80^{\circ} \mathrm{C}$ to yield a yellow suspension. The suspension was diluted with $\mathrm{CH}_{2} \mathrm{Cl}_{2}$ and filtered through a celite pad. The solvent was removed under reduced pressure and the product was purified using silica column and Hex:EtOAc $(1: 1)$ as eluent $\left(R_{f} \sim 0.40\right.$ - blue luminescent spot under long UV) and isolated as a yellow oil. Yield: $30 \mathrm{mg}$ (47 \%). 1H-NMR (CDCl $3,500 \mathrm{MHz}): 8.15$ (d, Cbz, $J=7.8 \mathrm{~Hz}, 2 \mathrm{H}), 7.77(\mathrm{~d}, \mathrm{Ph}, J=8.5 \mathrm{~Hz}, 2 \mathrm{H}), 7.66$ (s, py, 2H), $7.61(\mathrm{~d}, \mathrm{Ph}, J=8.6 \mathrm{~Hz}, 2 \mathrm{H}), 7.41-7.41(\mathrm{~m}, \mathrm{Cbz}, 4 \mathrm{H}), 7.31(\mathrm{t}, \mathrm{Cbz}, 2 \mathrm{H}), 4.20(\mathrm{q}, \mathrm{CH} 2, J=$ $7.2 \mathrm{~Hz}, 4 \mathrm{H}), 4.07$ (s, pyCH $2 \mathrm{~N}, 4 \mathrm{H}), 3.65\left(\mathrm{~s}, \mathrm{NCH}_{2}, 8 \mathrm{H}\right), 1.29\left(\mathrm{t}, \mathrm{CH}_{3}, J=7.1 \mathrm{~Hz}, 12 \mathrm{H}\right.$ ) ppm (Figure S3).

${ }_{13} \mathrm{C}\left\{{ }_{1} \mathrm{H}\right\}-\mathrm{NMR}\left(\mathrm{CDCl}_{3}, 125 \mathrm{MHz}\right): 171.1,158.8,140.5,138.3,133.4,132.4,126.9,126.1,123.6$, 123.1, 121.3, 120.3, 109.8, 92.5, 88.4, 60.6, 59.8, 55.0, 14.3 ppm (Figure S7). 
ESI-MS found (calc): $[\mathrm{M}+\mathrm{H}]+748$ (747).

Synthesis of 2,2',2",2"'-(4-((4-(9H-carbazol-9-yl)phenyl)ethynyl)pyridine-2,6-diyl)bis(methylene)bis(azanetriyl)tetraacetic acid $\left(\boldsymbol{H}_{4} \boldsymbol{C P A P}\right) .30 \mathrm{mg}(0.04 \mathrm{mmol})$ of $\mathbf{1 1}$ was dissolved in $2 \mathrm{~mL}$ of $\mathrm{MeOH}$ and $9 \mathrm{mg}(0.4 \mathrm{mmol}) \mathrm{NaOH}$ dissolved in $1 \mathrm{~mL}$ of water were added. The suspension was kept under stirring for $4 \mathrm{~h}$ at $50^{\circ} \mathrm{C}$. The $\mathrm{pH}$ of the reaction was adjusted by the addition of aqueous $\mathrm{HCl}$ (1 mol L-1) until $\mathrm{pH} \sim 3-4$, to yield a bright yellow precipitate that was filtered and washed with cold water, and was isolated as a bright yellow solid. Yield: $17 \mathrm{mg}$ (70 \%).

1H-NMR (DMSO- d6, 500 MHz): 8.27 (d, Cbz, $J=7.7 \mathrm{~Hz}, 2 \mathrm{H}), 7.93(\mathrm{~d}, \mathrm{Ph}, J=8.7 \mathrm{~Hz}, 2 \mathrm{H}), 7.75$ $(\mathrm{d}, \mathrm{Ph}, J=8.7 \mathrm{~Hz}, 2 \mathrm{H}), 7.62(\mathrm{~s}, \mathrm{py}, 2 \mathrm{H}), 7.48-7.46(\mathrm{~m}, \mathrm{Cbz}, 4 \mathrm{H}), 7.35-7.31(\mathrm{~m}, \mathrm{Cbz}, 2 \mathrm{H}), 3.98$ (s, pyCH2 $\left.\mathrm{N}_{2} 4 \mathrm{H}\right), 3.51$ (s, $\left.\mathrm{NCH}_{2}, 8 \mathrm{H}\right) \mathrm{ppm}$.

${ }_{13 \mathrm{C}}\left\{{ }_{1} \mathrm{H}\right\}-\mathrm{NMR}$ (DMSO-d6, $125 \mathrm{MHz}$ ): 172.4, 159.2, 139.6, 137.7, 133.5, 130.9, 126.8, 126.3, $122.9,122.3,120.5,120.0,109.6,92.3,88.0,58.9,54.4 \mathrm{ppm}$.

ESI-MS found (calc): $[\mathrm{M}+\mathrm{H}]+635$ (635).

Synthesis of the $K_{3}\left[\operatorname{Ln}(C P A D)_{3}\right]$ complexes $\left(\operatorname{Ln}=\right.$ EuIII and $\left.G d_{I I I}\right) .0 .035 \mathrm{mmol}$ of $\mathbf{H 2} \mathbf{C P A D}$ was dissolved in $3 \mathrm{~mL}$ of DMF: $\mathrm{H}_{2} \mathrm{O}(85: 15 \mathrm{v} / \mathrm{v})$, followed by the addition of $0.035 \mathrm{mmol} \mathrm{K}_{2} \mathrm{CO}_{3}$ and stirred for $30 \mathrm{~min}$ at $70{ }^{\circ} \mathrm{C} .0 .012 \mathrm{mmol} \mathrm{LnCl}_{3}$ was added and the system stirred for $12 \mathrm{~h}$ at $80{ }^{\circ} \mathrm{C}$. The bright yellow solution was filtered, the solvent removed under reduced pressure and the solid washed with cold water to yield yellow solids. Yield: $85 \%$.

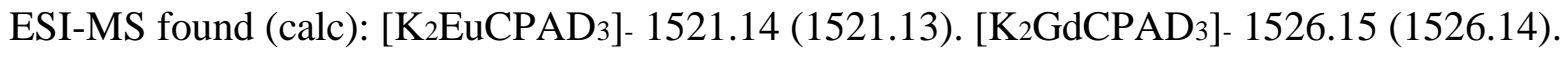


Synthesis of the $\mathrm{K}\left[\mathrm{Ln}(\mathrm{CPAP})\left(\mathrm{H}_{2} \mathrm{O}\right)_{2}\right]$ complexes $(\mathrm{Ln}=$ EuIII, YbIII and GdIII). $0.035 \mathrm{mmol}$ of H4CPAP was dissolved in $3 \mathrm{~mL}$ of DMF: $\mathrm{H}_{2} \mathrm{O}(90: 10 \mathrm{v} / \mathrm{v})$, followed by the addition of $0.070 \mathrm{mmol}$ $\mathrm{K}_{2} \mathrm{CO}_{3}$ and stirred for $30 \mathrm{~min}$ at $70{ }^{\circ} \mathrm{C} .0 .035 \mathrm{mmol} \mathrm{LnCl}_{3}$ was added and the system stirred for 12 $\mathrm{h}$ at $80{ }^{\circ} \mathrm{C}$. The bright yellow solution was filtered, the solvent removed under reduced pressure and the solid washed with cold water to yield yellow solids. Yield: $70 \%$.

ESI-MS found (calc): [Eu(CPAP)]- 783.11 (783.10). $\quad$ [Gd(CPAP)]- 788.10 (788.10). [Yb(CPAP)(DMSO)2]- 960.05 (960.14). [Yb(CPAP)]- 804.11 (804.11).

Photophysical characterization. The absorption spectra of the compounds were obtained in a Perkin Elmer Lambda 35 spectrometer using DMSO or TRIS/HCl aqueous solution ( $\mathrm{pH} \sim 7.4,10 \%$ DMSO) as the solvent. Solutions with concentrations 1x10-4 M were used to obtain the emission and excitation spectra. The photoluminescence data were obtained in a Fluorolog-3 spectrofluorimeter (Horiba FL3-22-iHR550), with an excitation monochromator with 1200 grooves $/ \mathrm{mm}$ and gratings blazed at $330 \mathrm{~nm}$ and an emission monochromator with 1200 grooves $/ \mathrm{mm}$ and gratings blazed at $500 \mathrm{~nm}$. An ozone-free $450 \mathrm{~W}$ xenon lamp (Ushio) was used as radiation source. The excitation spectra, corrected for instrumental function, were measured between 250 and $500 \mathrm{~nm}$. The emission spectra were measured in the range 550-725 $\mathrm{nm}$ using a Hamamatsu 928P detector. All emission spectra were corrected for instrumental function. The emission decay curves were obtained using a TCSPC system and a Xe pulsed lamp as excitation source. The energies of the ligands' singlet and triplet levels were obtained at $\sim 77 \mathrm{~K}$ by deconvolution of the fluorescence and phosphorescence spectra, respectively, into their FranckCondon progression and are reported as the $0-0$ transition. 8 The quantum yield of the sensitized emission $\left(\phi_{L}^{E u}\right)$ of the EuIII complexes was determined using an integrating sphere (model F-3018) 
coupled directly to the spectrofluorimeter. A solution containing only the solvent was used as blank, and then, replaced by a solution containing the compound. The sample was measured on- and -outof-the beam path in order to account for any re-absorption effects. The quantum yield of the samples was determined using Equation S1.

$$
\Phi=\frac{\left(I_{B}-I_{S}\right)}{\left(L_{S}-L_{B}\right)} \times 100
$$

$L$ and $E$ are the scattering and emission integrated areas, respectively. The subscripts $B$ and $S$ stand for blank and sample, respectively.

For YbIII complexes the standard for quantum yield measurements was $\left[\mathrm{Yb}(\mathrm{tta})_{3}\left(\mathrm{H}_{2} \mathrm{O}\right)_{2}\right](\phi \sim 0.12$, in air-saturated toluene).12 The excitation wavelength for samples and quantum yield standard were chosen to ensure a linear relationship between the intensity of emitted light and the concentration of the absorbing/emitting species $(A \leq 0.05)$. The quantum yield of the samples was determined by the dilution method using Equation S2.

$$
\Phi_{x}=\frac{\operatorname{Grad}_{x}}{\operatorname{Grad}_{s t d}} \times \frac{n_{x}^{2}}{n_{s t d}^{2}} \times \frac{I_{s t d}}{I_{x}} \Phi_{s t d}
$$

Grad is the slope of the plot of the emission area as a function of absorbance, $n$ is the refractive index of the solvent, $I$ is the intensity of the excitation source at the excitation wavelength and $\Phi$ is the quantum yield for sample $x$ and standard std.

The intrinsic quantum yield $\phi_{E u}^{E u}$ was determined using equation S3.

$$
\phi_{E u}^{E u}=\frac{A_{r a d}}{A_{\text {tot }}}
$$

Atot is the total emission rate $\left(A_{t o t}=k_{R}+k_{N R}=1 / \tau_{\text {exp }}\right)$.

The sensitization efficiency ( $\left.\eta_{\text {sens }}\right)$ was determined using equation S4.

$$
\eta_{\text {sens }}=\frac{\phi_{L}^{E u}}{\phi_{E u}^{E u}}
$$


The number of coordinated water $(q)$ was determined using equation S5.7

$$
q=1.1 \times\left(\frac{1}{\tau_{H 2 O}}-\frac{1}{\tau_{D 2 O}}-0.31\right)
$$

$\tau_{H 2 O}$ and $\tau_{D 2 O}$ are the emission lifetimes in water and deuterated water, respectively.

The photostability of the EuIII complexes, in solution, was evaluated over a $1 \mathrm{~h}$ period by measuring the intensity of the ${ }_{5} \mathrm{D}_{0} \rightarrow{ }_{7} \mathrm{~F}_{2}$ transition under constant illumination $(450 \mathrm{~W}$ xenon lamp, $\lambda$ exc $=$ $380 \mathrm{~nm})$, at $25^{\circ} \mathrm{C}$.

Two-photon emission setup. A Spectraphysics Mai Tai Ti:Sapphire tunable laser generates 80 fs excitation pulses centered between $710 \mathrm{~nm}$ and $820 \mathrm{~nm}$. This excitation pulse propagates toward a pair of chirped mirrors (Femtolasers GSM216), introduced to compensate for any dispersion introduced from other optics. A half wave plate (Thorlabs WPH10M-780) was placed in the beam path and set to the magic angle in order to remove polarization dependence. To modulate the power, neutral density filters was utilized with ODs varying between 0.4 and 0.8 . The incident pulse was focused using a $100 \mathrm{~mm}$ convex lens (Thorlabs LA1509) into the center of a $1 \mathrm{~cm}$ quartz sample cell. The emission of the sample was collected at a right angle by a reflective objective $(20 \mathrm{x}$ magnification) and focused into an Ocean Optics USB2000+ UV-VIS Spectrometer. The typical spectral range used on the spectrometer was $180 \mathrm{~nm}$ to $870 \mathrm{~nm}$. The excitation wavelengths of 720 $\mathrm{nm}$ and $750 \mathrm{~nm}$ were chosen for linearity of signal with sample concentration as well as to enable direct comparison of the EuII complexes with the 2PA rhodamine B standard.

Two-photon absorption cross section. The two photon absorption cross sections for all compounds were determined via a Two-Photon Excited Fluorescence (TPEF) procedure using equation $\mathrm{S} 6.13$

$$
\sigma_{2 P A}=\frac{F}{F^{r}} \frac{\phi^{r}}{\phi} \frac{c^{r}}{c} \sigma_{2 P A}^{r}
$$


$\mathrm{F}$ are the emission intensities, $c$ is the concentration, and $r$ denotes the reference. For the EuIII complexes $\phi=\phi_{L}^{E u}$. Rhodamine B in methanol was used as the reference at $750 \mathrm{~nm}$ with $\phi^{r}=$ $70 \%$ and $\sigma_{2 P A}^{r}=67 \mathrm{GM} .14$ The concentration of the reference was varied between 0.1 and $1 \mathrm{mM}$. The cross sections of $\mathrm{K}_{3}\left[\mathrm{Eu}(\mathrm{CPAD})_{3}\right](0.1 \mathrm{mM})$ and $\mathrm{K}\left[\mathrm{Eu}(\mathrm{CPAP})(\mathrm{DMSO})_{2}\right](0.1 \mathrm{mM})$ in DMSO were determined by exciting the sample at $750 \mathrm{~nm}$ followed by collecting the spectra using an integration time of 2 seconds, a boxcar width of 2 pixels, and a power of $160 \mathrm{~mW}$. The data for $\mathrm{K}\left[\mathrm{Eu}(\mathrm{CPAP})\left(\mathrm{H}_{2} \mathrm{O}\right)_{2}\right](0.1 \mathrm{mM})$ in $\mathrm{TRIS} / \mathrm{HCl}$ aqueous solution $(\mathrm{pH} \sim 7.4,10 \% \mathrm{DMSO})$ was collected with an integration time of 10 seconds and a boxcar width of 2 , with power ranging from $200 \mathrm{~mW}$ to $270 \mathrm{~mW}$ and excited at $750 \mathrm{~nm}$. The intensity for all samples was determined by integrating the spectrum from $550 \mathrm{~nm}$ to $715 \mathrm{~nm}$.

Emission Intensity Dependence. The laser power was varied between $50 \mathrm{~mW}$ and $420 \mathrm{~mW}$ to determine the effect of the laser power on the intensity of the spectrum at $615 \mathrm{~nm}$. The power dependence for $\mathrm{K}_{3}\left[\mathrm{Eu}(\mathrm{CPAD})_{3}\right], \quad \mathrm{K}\left[\mathrm{Eu}(\mathrm{CPAP})(\mathrm{DMSO})_{2}\right]$ and $\mathrm{K}\left[\mathrm{Eu}(\mathrm{CPAP})\left(\mathrm{H}_{2} \mathrm{O}\right)_{2}\right]$ was determined at an excitation wavelength of $750 \mathrm{~nm}$. Similar collection parameters were utilized as described above for the two-photon cross section measurements. All spectra were found to have a linear relationship between the $\log$ of the intensity and the $\log$ of the power at the $\lambda_{\max }$. The experimental linear regression coefficients are summarized in Table S2.

Excitation Scans. For all samples, the intensity at $615 \mathrm{~nm}$ was collected upon excitation between $710 \mathrm{~nm}$ and $820 \mathrm{~nm}$. Similar collection parameters were used as described above.

Viscosity Sensing Measurements. $0.2 \mathrm{mM}$ solutions of $\mathrm{K}_{3}\left[\mathrm{Eu}(\mathrm{CPAD})_{3}\right]$ were prepared in different mixtures of methanol and glycerol to obtain a wide range of viscosities. The emission spectra were obtained exciting at $336 \mathrm{~nm}$ (for one-photon absorption) or at $720 \mathrm{~nm}$ (for two-photon 
excitation, $P=235 \mathrm{~mW}$ ). The intensity of the ${ }_{5} \mathrm{D}_{0} \rightarrow{ }_{7} \mathrm{~F}_{2}$ transition was plotted as a function of the viscosity.

\section{H-NMR spectra}

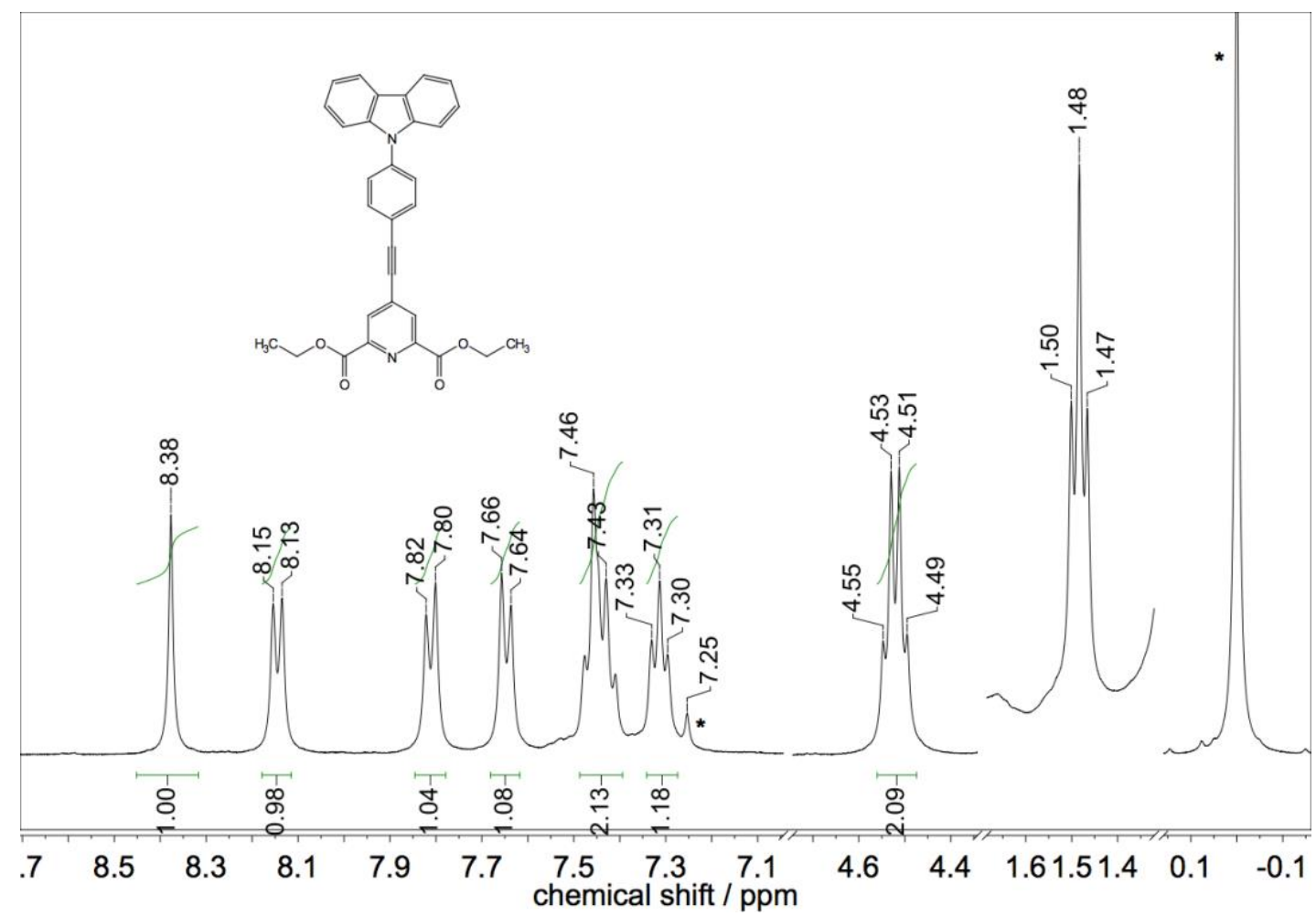

Figure S1. $1 \mathrm{H}-\mathrm{NMR}$ of 6. 


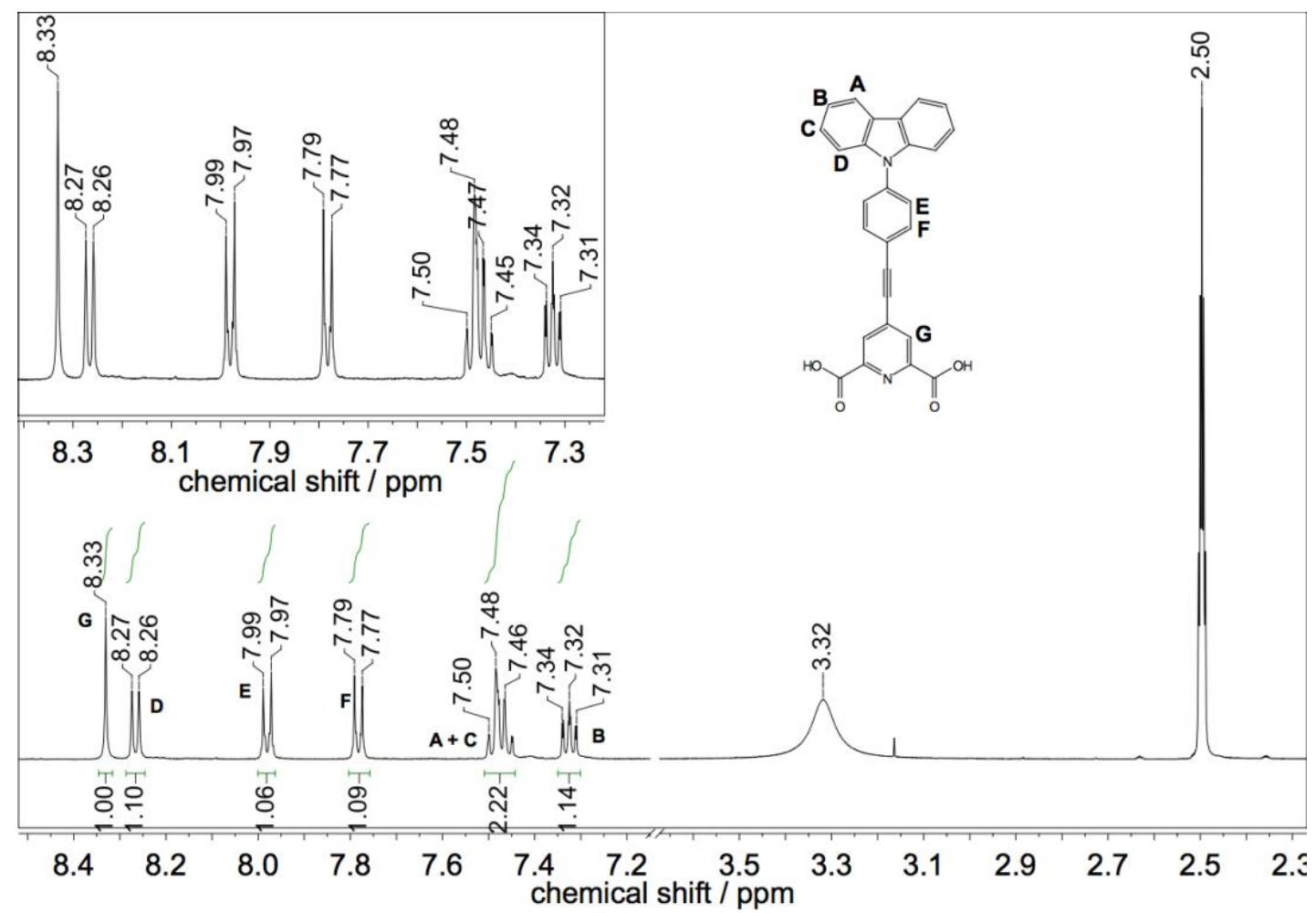

Figure S2. $1 \mathrm{H}-\mathrm{NMR}$ of $\mathbf{H}_{2}$ CPAD.

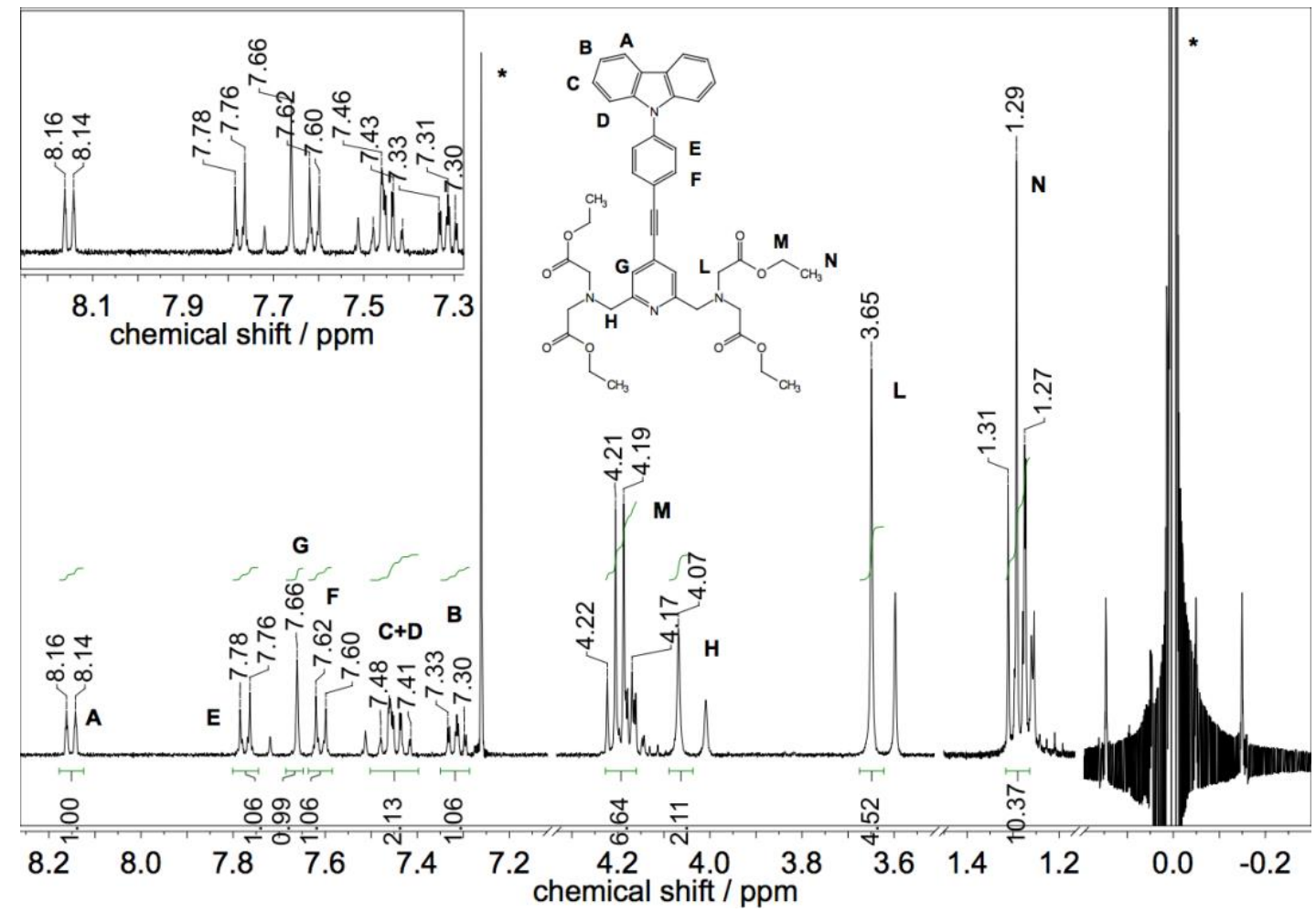

Figure S3. 1H-NMR of 11. 


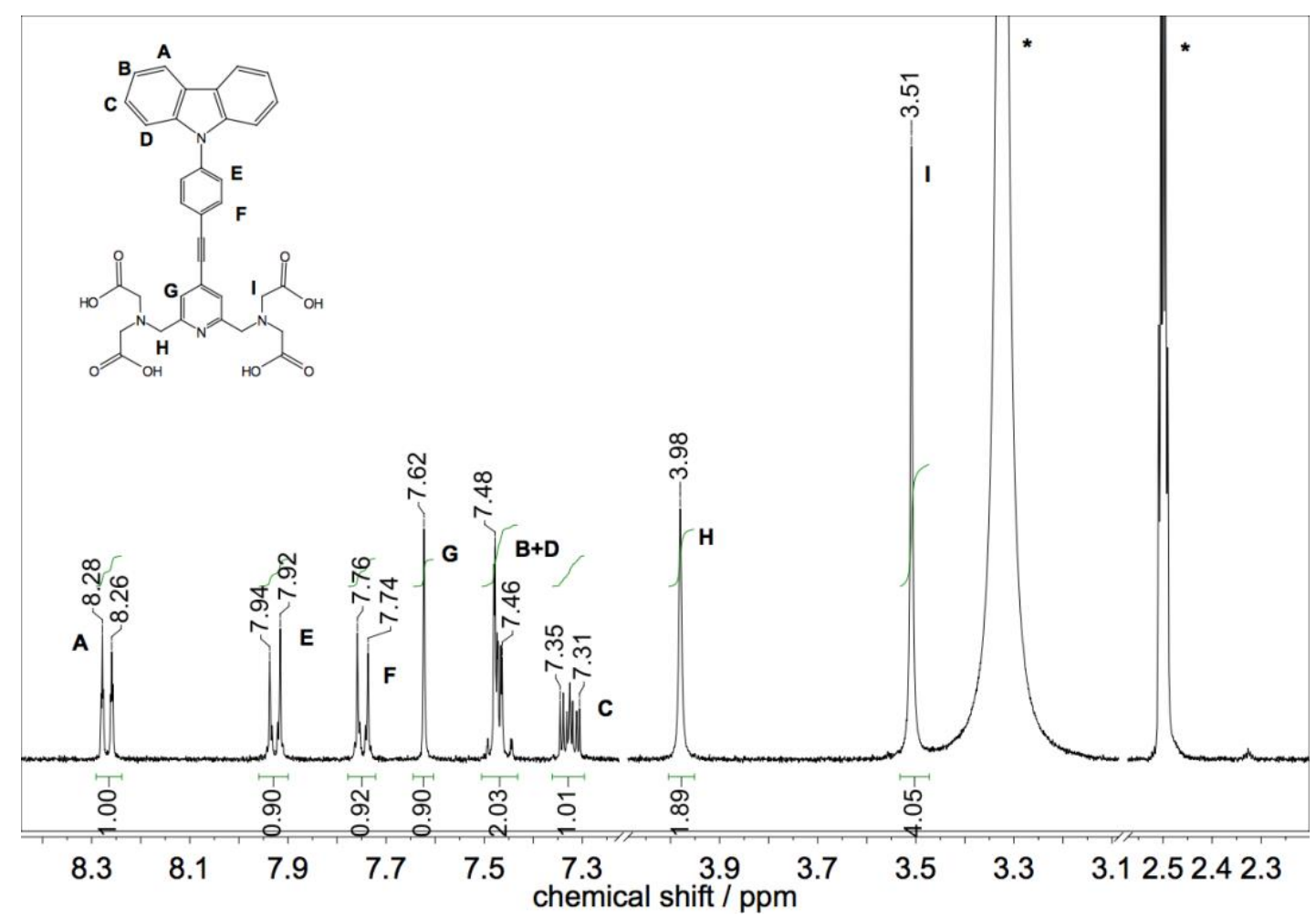

Figure S4. $1 \mathrm{H}-\mathrm{NMR}$ of $\mathrm{H}_{4} \mathrm{CPAP}$.

\section{C-NMR}




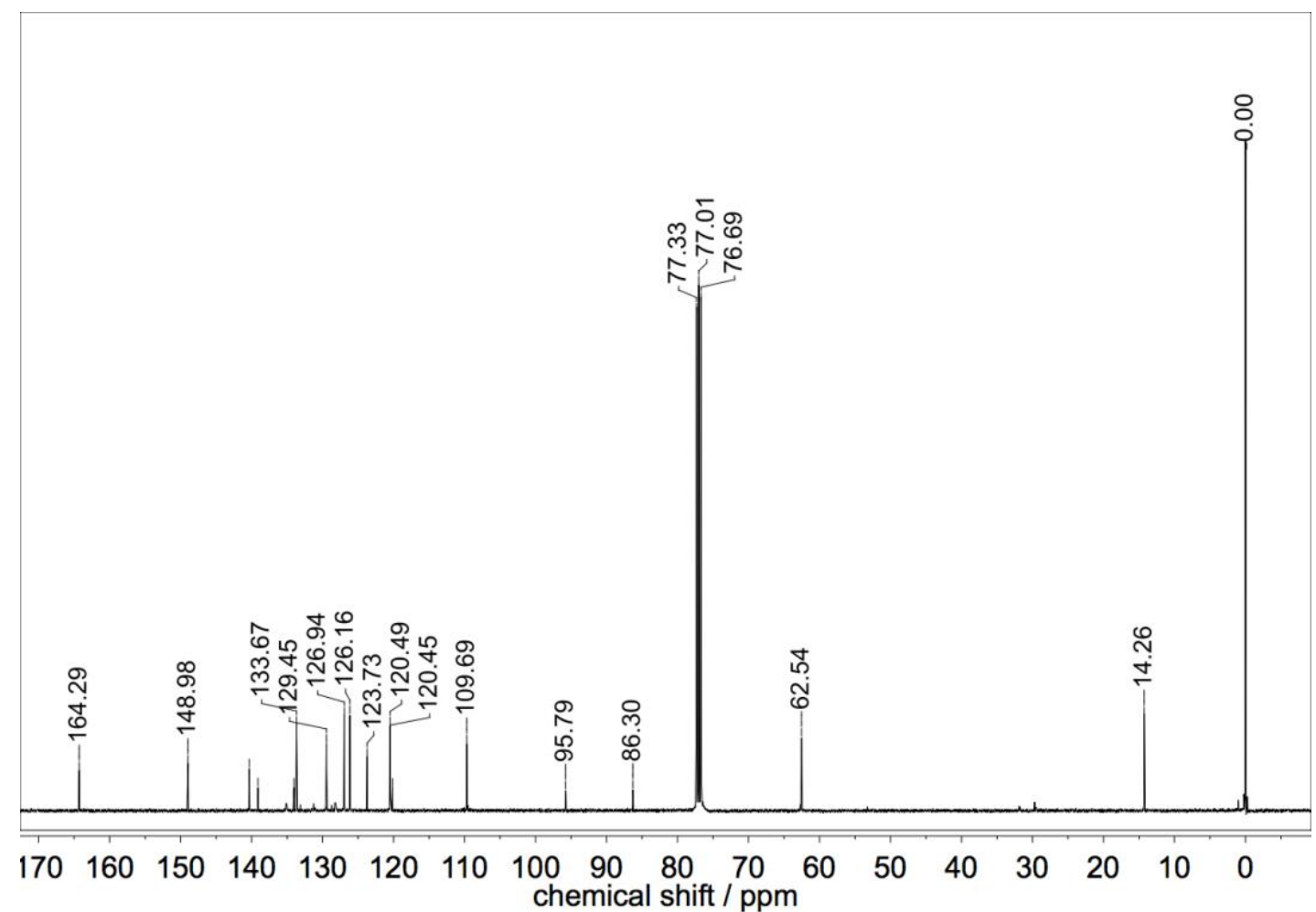

Figure S5. 13C-NMR of 6.

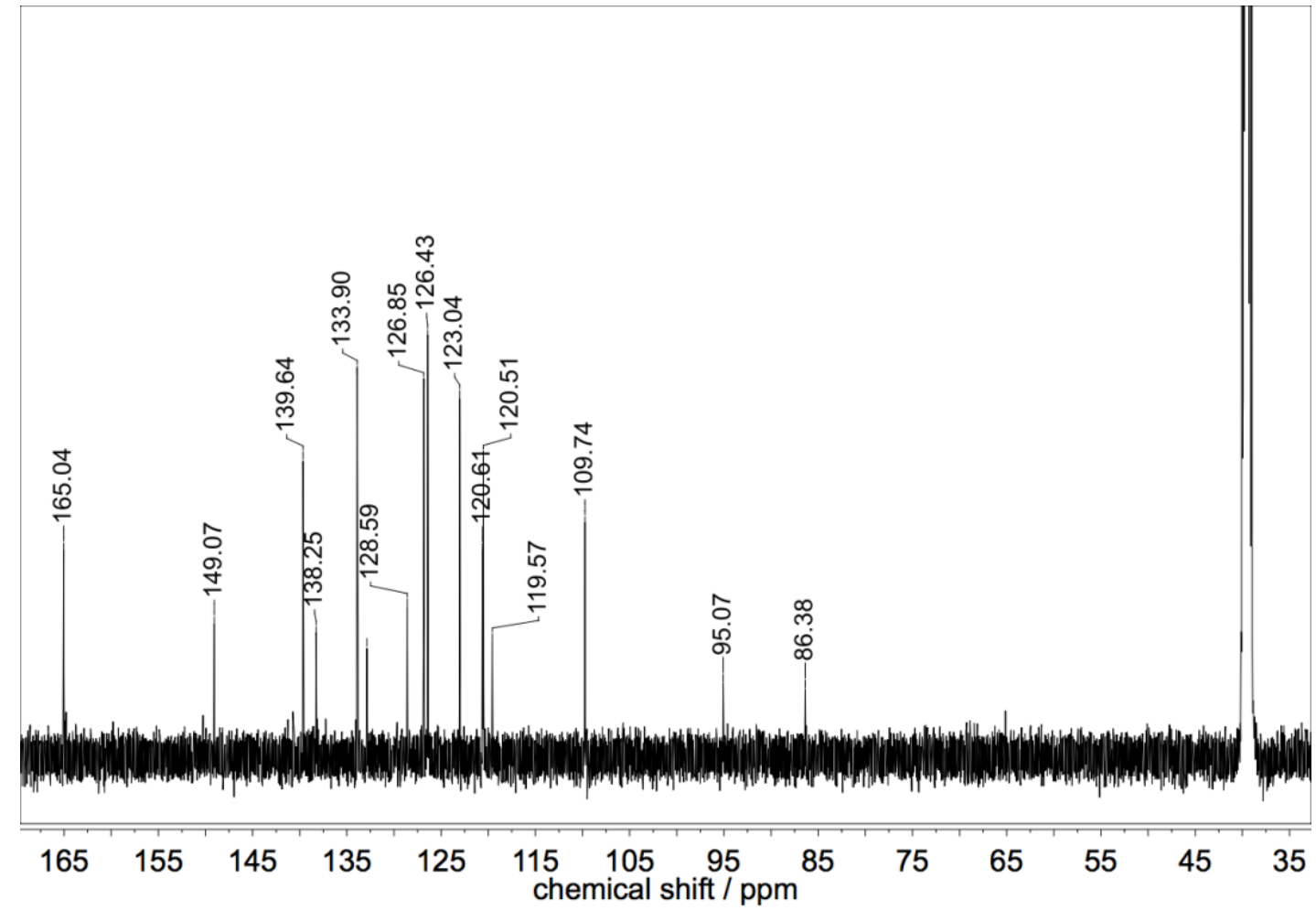

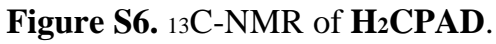




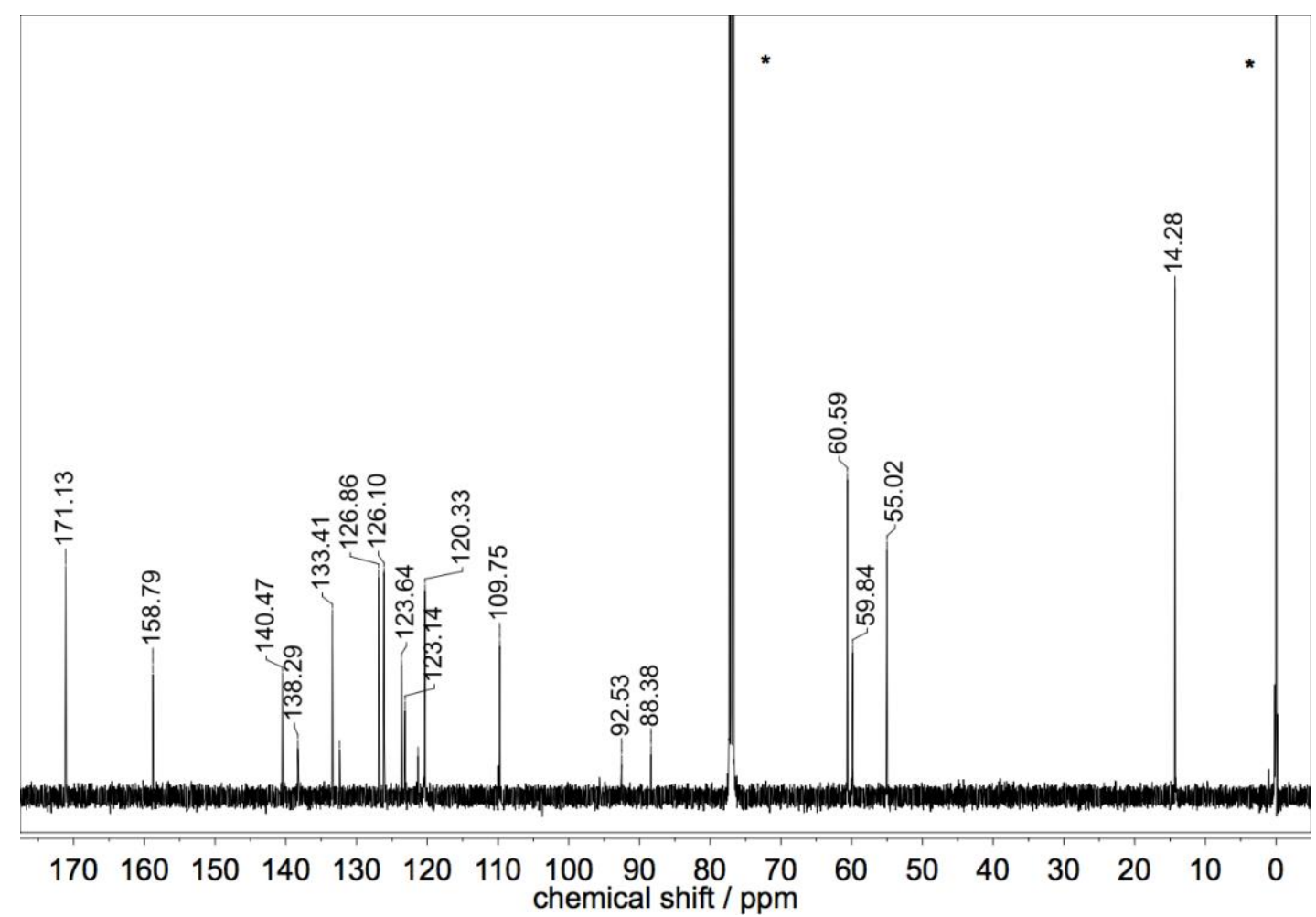

Figure S7. 13C-NMR of 11.

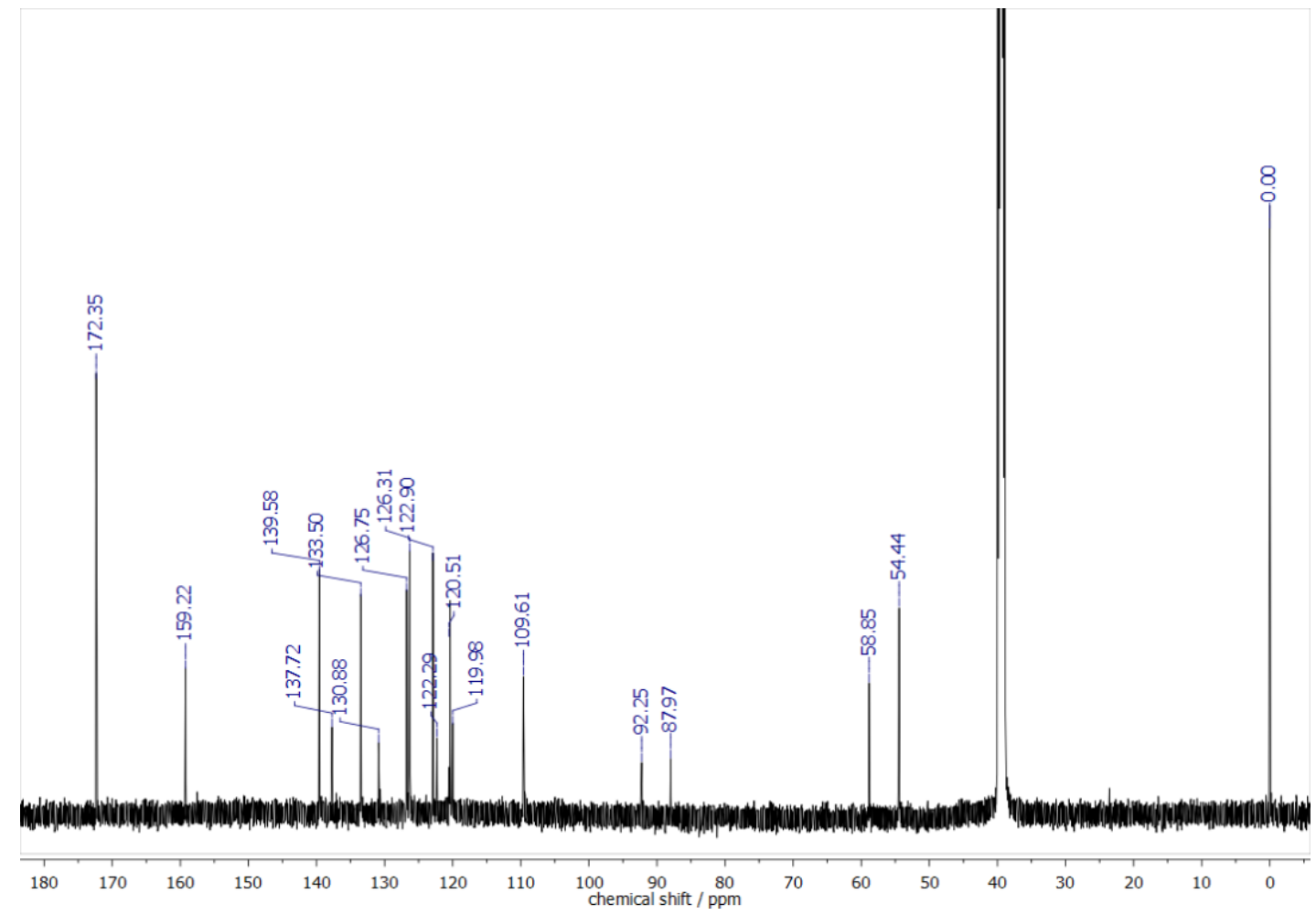

Figure S8. ${ }_{13} \mathrm{C}-\mathrm{NMR}$ of $\mathrm{H}_{4} \mathrm{CPAP}$. 


\section{ESI-mass spectra}

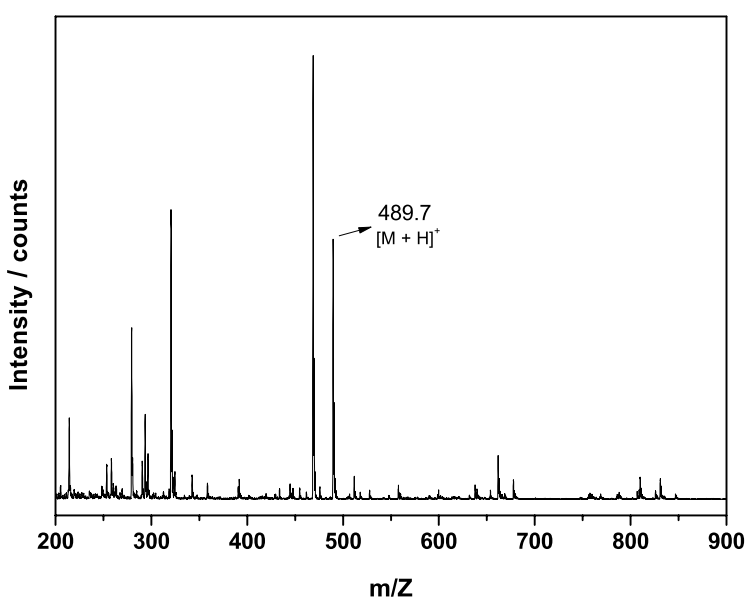

(a)

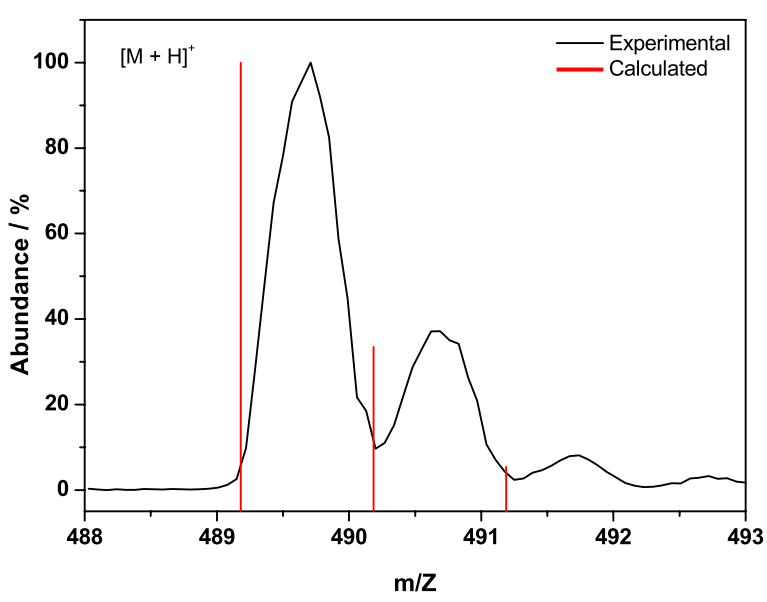

(b)

Figure S9. (a) ESI-MS of 6. (b) Isotope pattern.

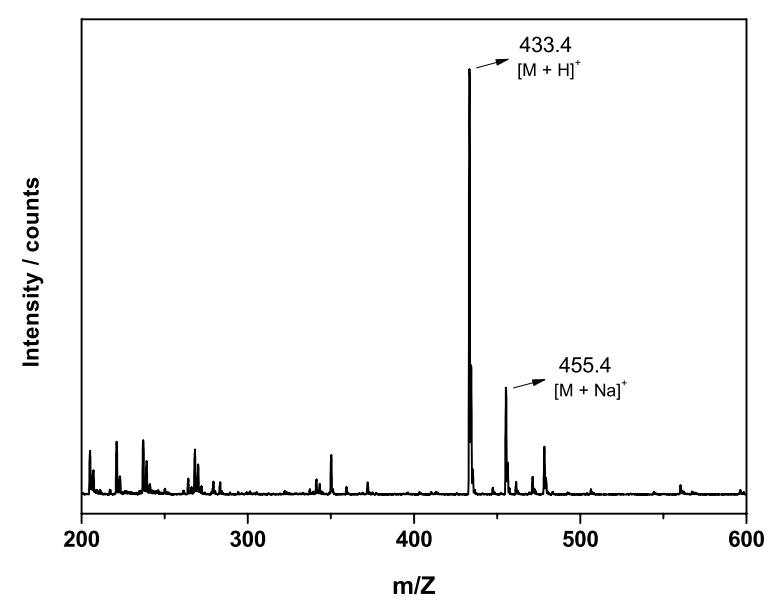

(a)

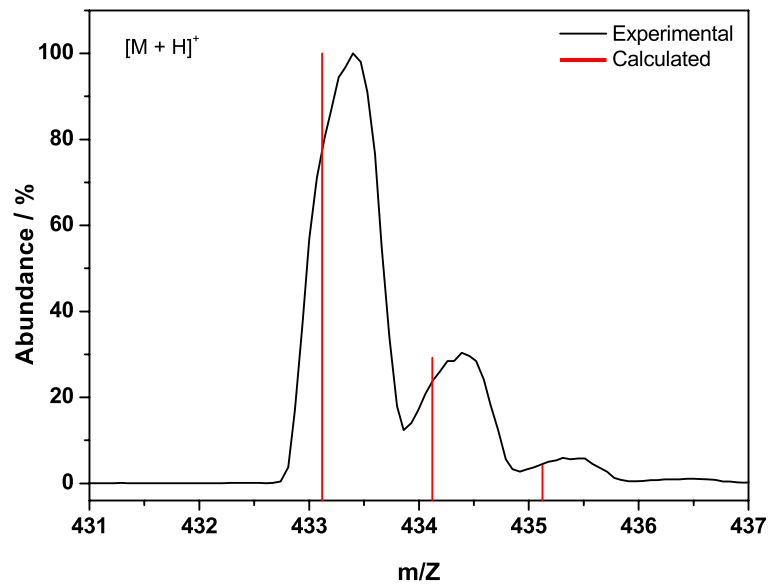

(b)

Figure S10. (a) ESI-MS of $\mathbf{H}_{2}$ CPAD. (b) Isotope pattern. 


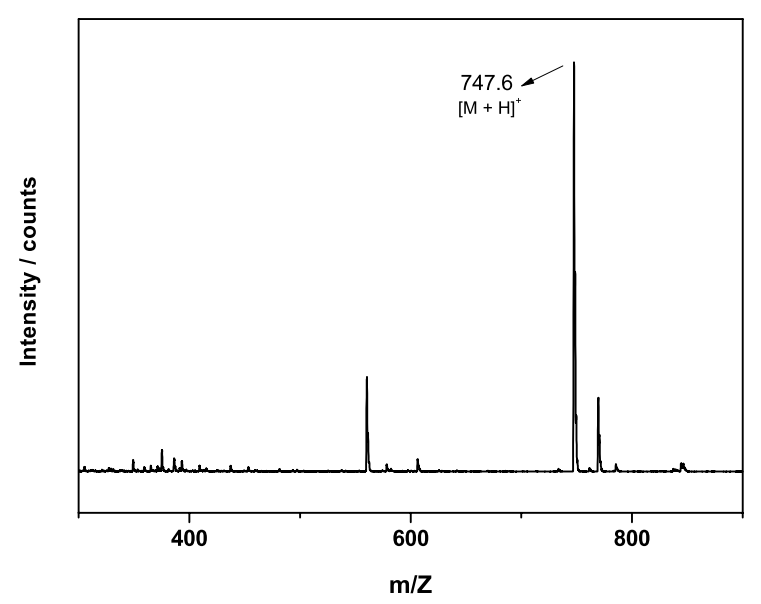

(a)

Figure S11. (a) ESI-MS of 11. (b) Isotope pattern.

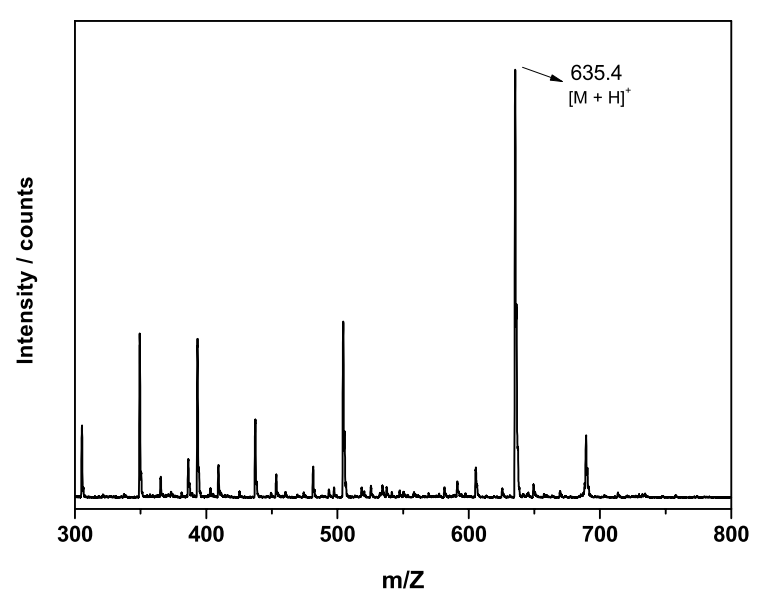

(a)

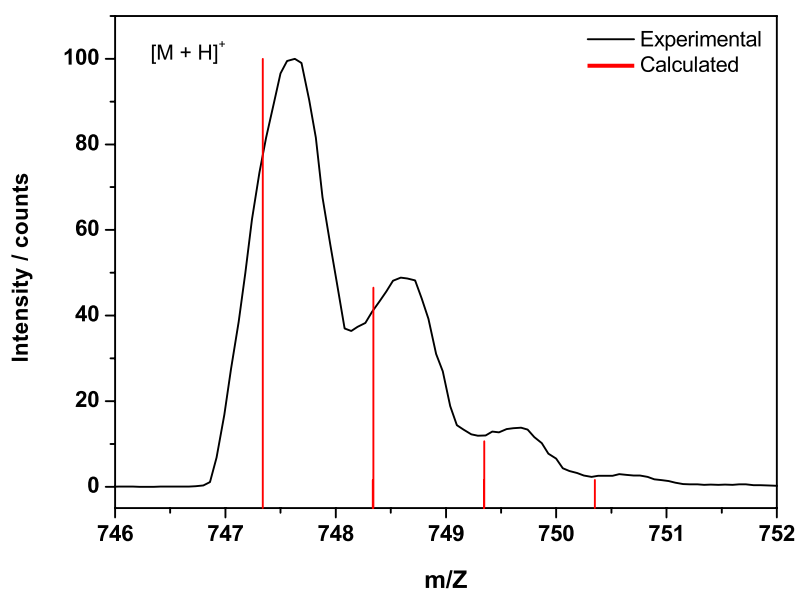

(b)

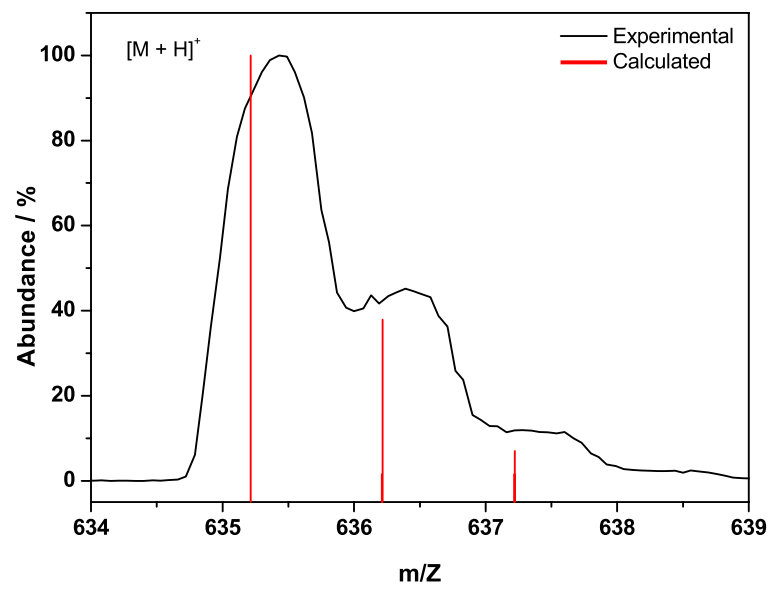

(b)

Figure S12. (a) ESI-MS of $\mathrm{H}_{4}$ CPAP. (b) Isotope pattern.

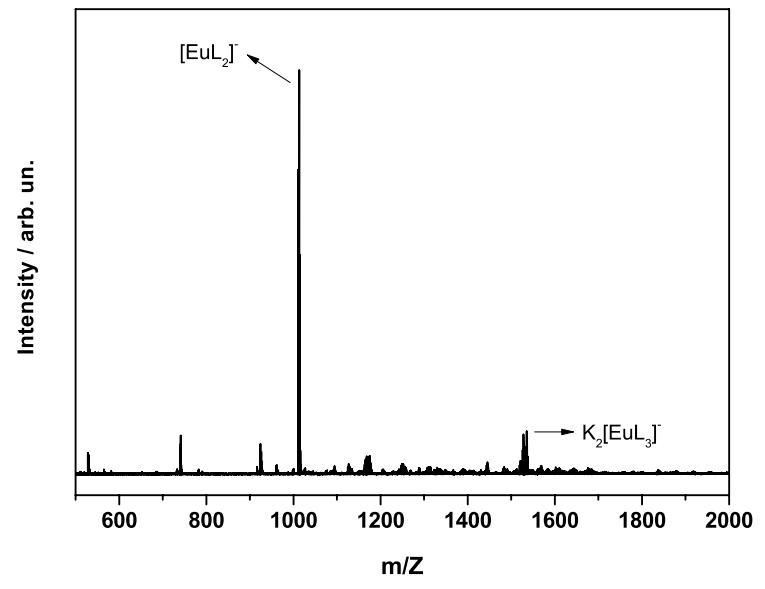

(a)

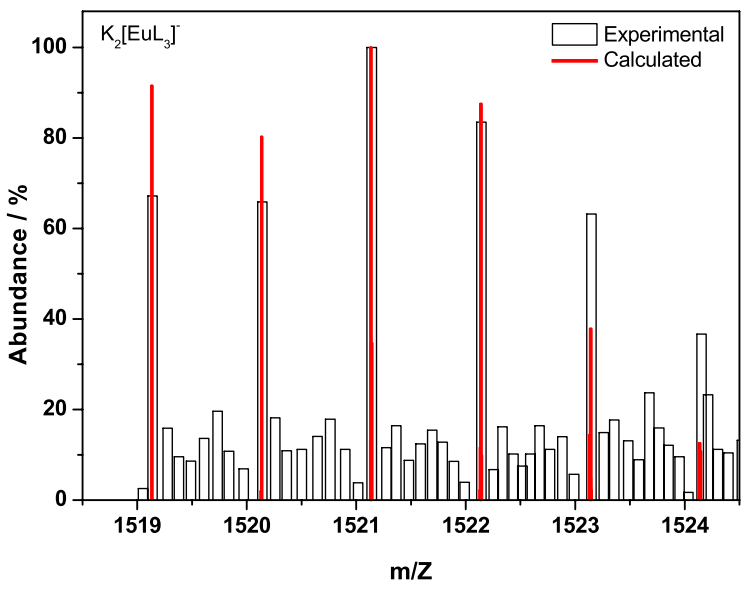

(b)

Figure S13. (a) ESI-MS of $\mathrm{K}_{3}\left[\mathrm{Eu}(\mathrm{CPAD})_{3}\right]$. (b) Isotope pattern. 


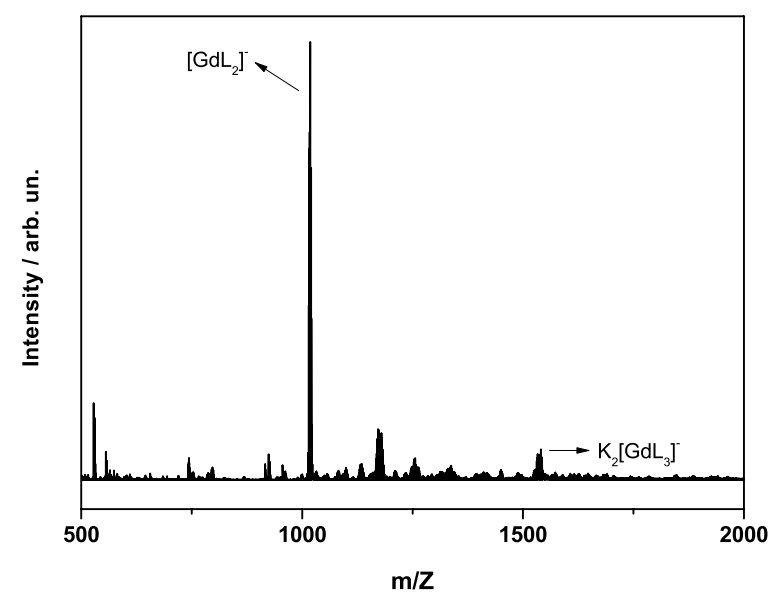

(a)

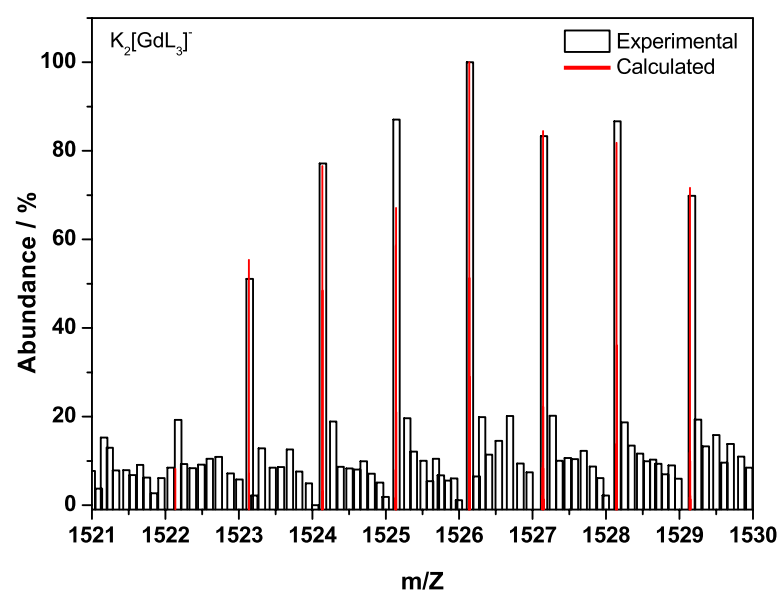

(b)

Figure S14. (a) ESI-MS of $\mathrm{K}_{3}\left[\mathrm{Gd}(\mathrm{CPAD})_{3}\right]$. (b) Isotope pattern.

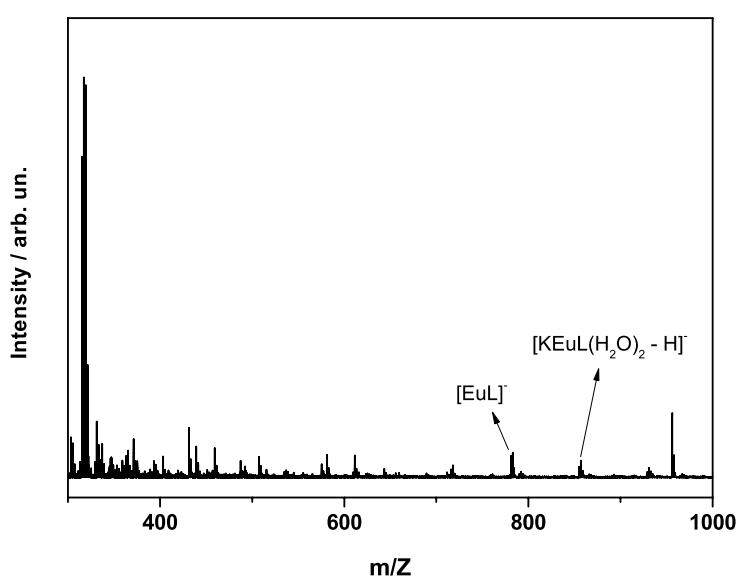

(a)

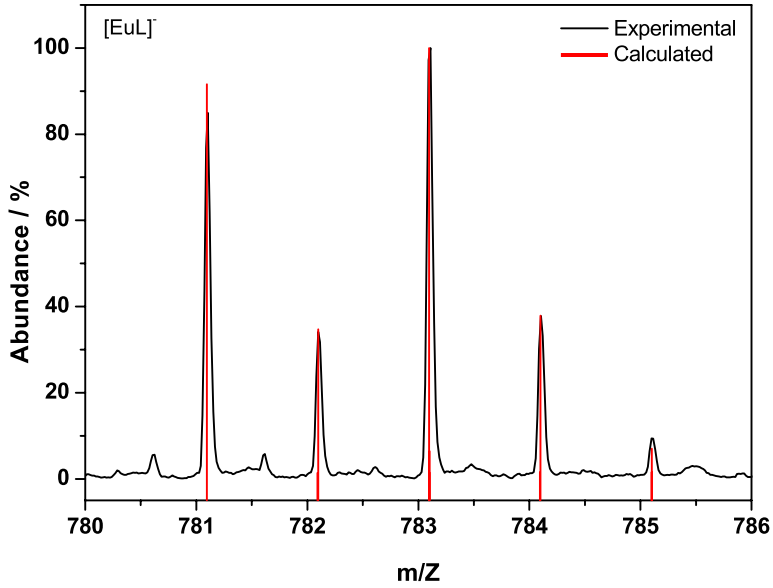

(b)

Figure S15. (a) ESI-MS of $\mathrm{K}\left[\mathrm{Eu}(\mathrm{CPAP})\left(\mathrm{H}_{2} \mathrm{O}\right)_{2}\right]$. (b) Isotope pattern.

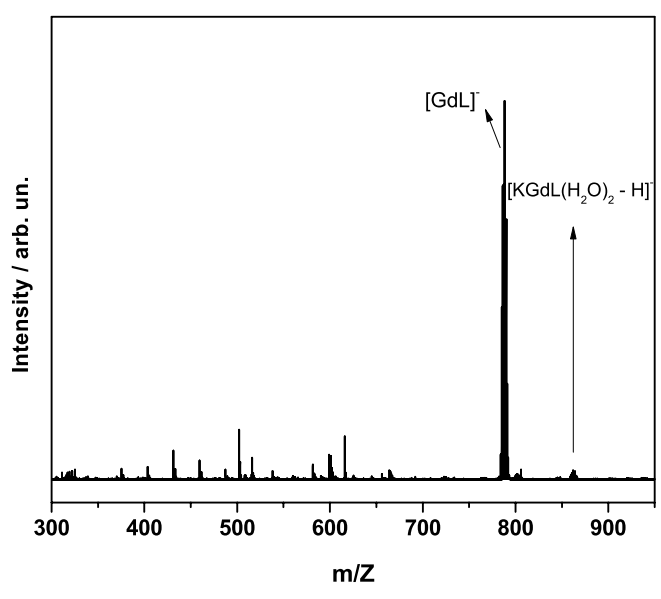

(a)

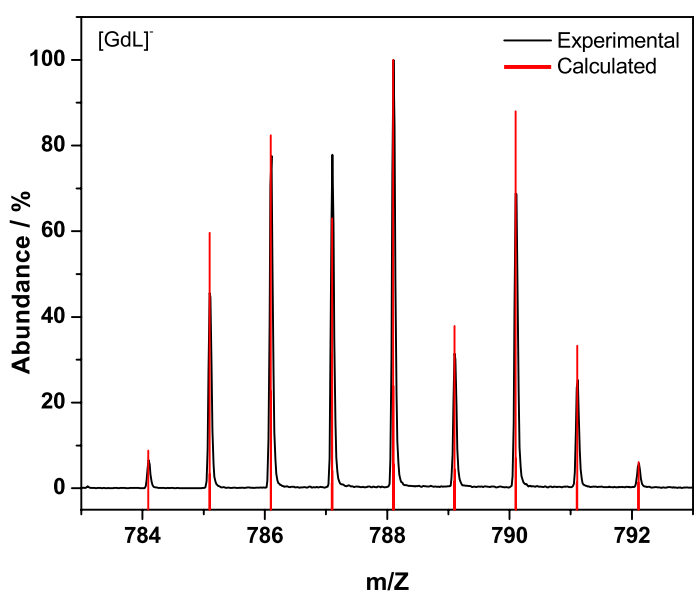

(b)

Figure S16. (a) ESI-MS of $\mathrm{K}\left[\mathrm{Gd}(\mathrm{CPAP})\left(\mathrm{H}_{2} \mathrm{O}\right)_{2}\right]$. (b) Isotope pattern. 


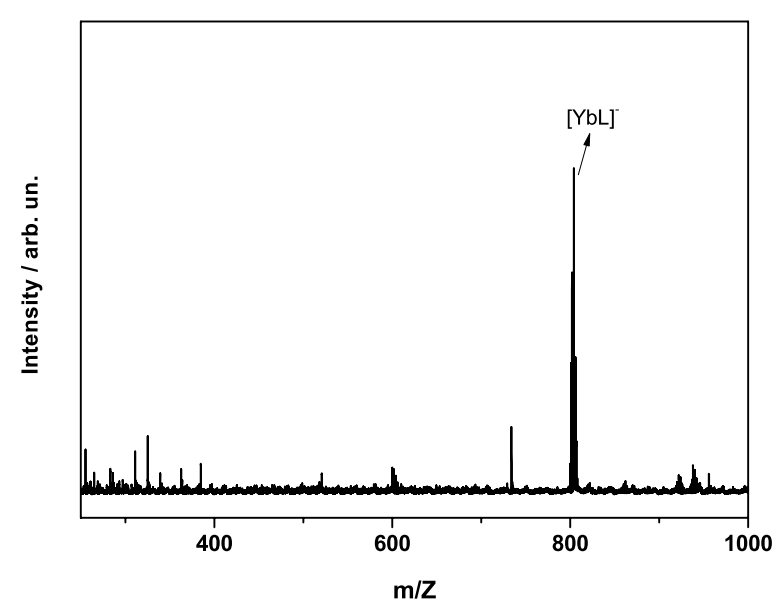

(a)

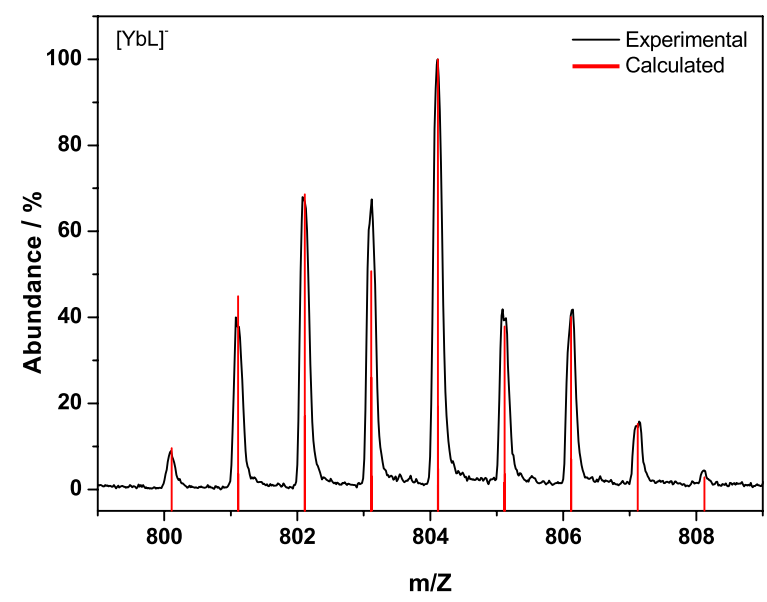

(b)

Figure S17. (a) ESI-MS of $\mathrm{K}\left[\mathrm{Yb}(\mathrm{CPAP})\left(\mathrm{H}_{2} \mathrm{O}\right)_{2}\right]$. (b) Isotope pattern.

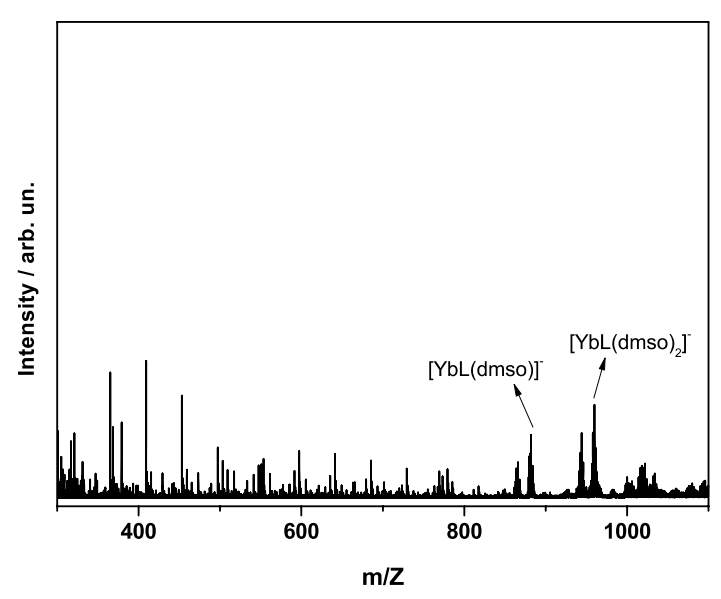

(a)

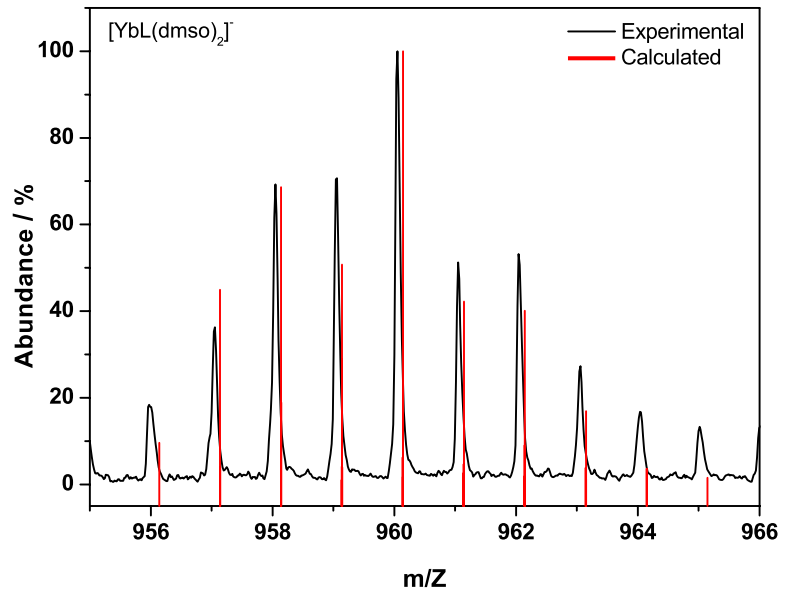

(b)

Figure S18. (a) ESI-MS of K[Yb(CPAP)(DMSO)2]. (b) Isotope pattern.

\section{Photophysical characterization}




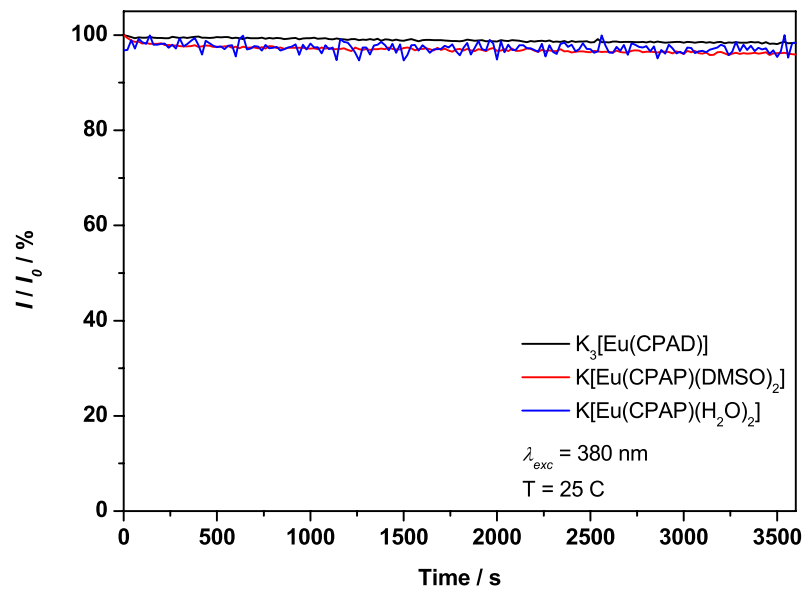

Figure S19. Photostability of the complexes $\mathrm{K}_{3}\left[\mathrm{Eu}(\mathrm{CPAD})_{3}\right]$ (black line), $\mathrm{K}\left[\mathrm{Eu}(\mathrm{CPAP})(\mathrm{DMSO})_{2}\right.$ (red line) and $\mathrm{K}\left[\mathrm{Eu}(\mathrm{CPAP})\left(\mathrm{H}_{2} \mathrm{O}\right)_{2}\right]$ (blue line). $\lambda_{e x c}=380 \mathrm{~nm}$ and $\mathrm{T}=25^{\circ} \mathrm{C}$.

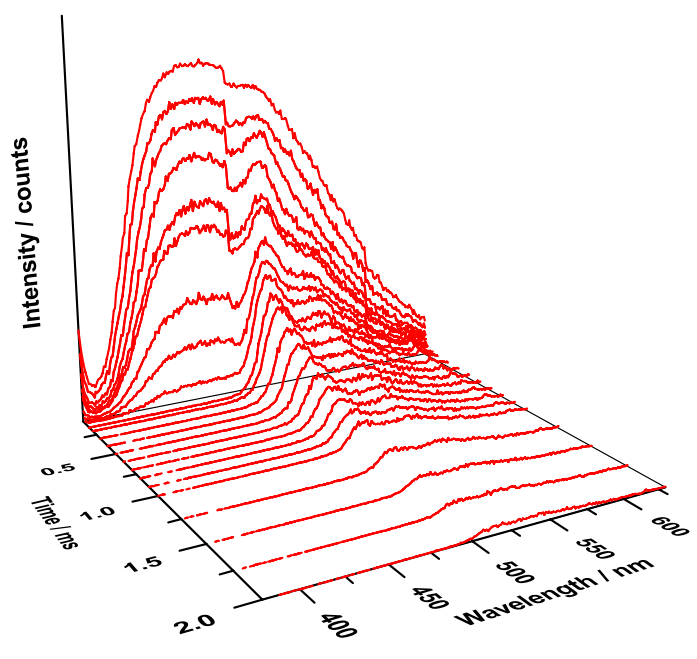

(a)

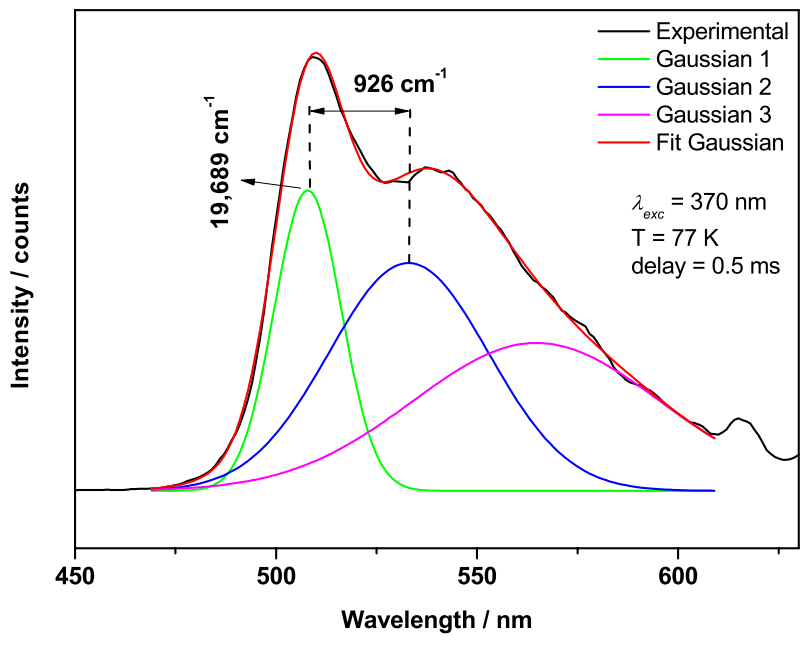

(b)

Figure S20. (a) Time-resolved phosphorescence spectra of $\mathrm{K}_{3}\left[\mathrm{Gd}(\mathrm{CPAD})_{3}\right]$ at $\sim 77 \mathrm{~K}$. (b) Deconvolution of the phosphorescence band into its vibrational components. 


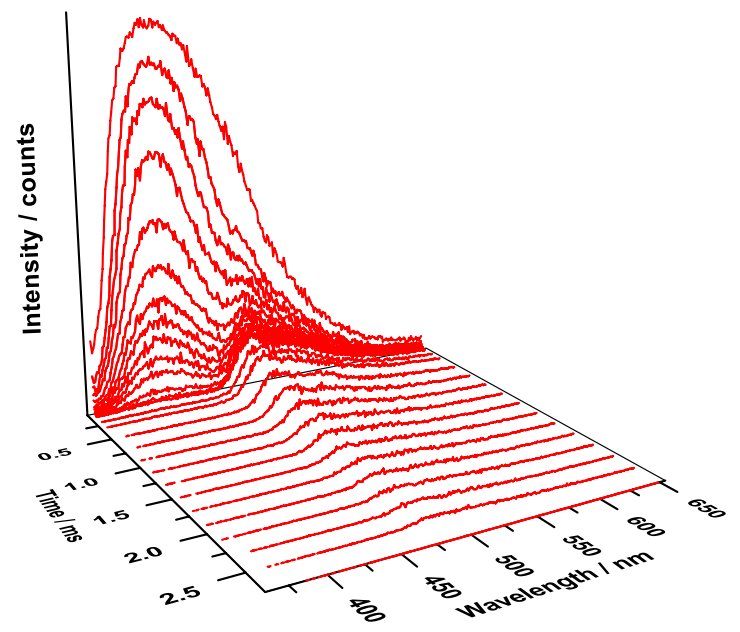

(a)

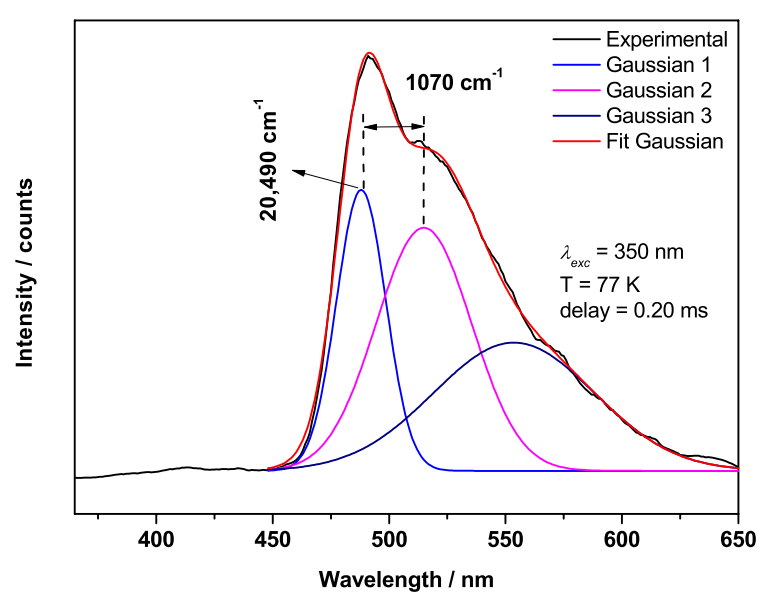

(b)

Figure S21. (a) Time-resolved phosphorescence spectra of $\mathrm{K}\left[\mathrm{Gd}(\mathrm{CPAP})\left(\mathrm{H}_{2} \mathrm{O}\right)_{2}\right]$ at $\sim 77 \mathrm{~K}$. (b) Deconvolution of the phosphorescence band into its vibrational components.

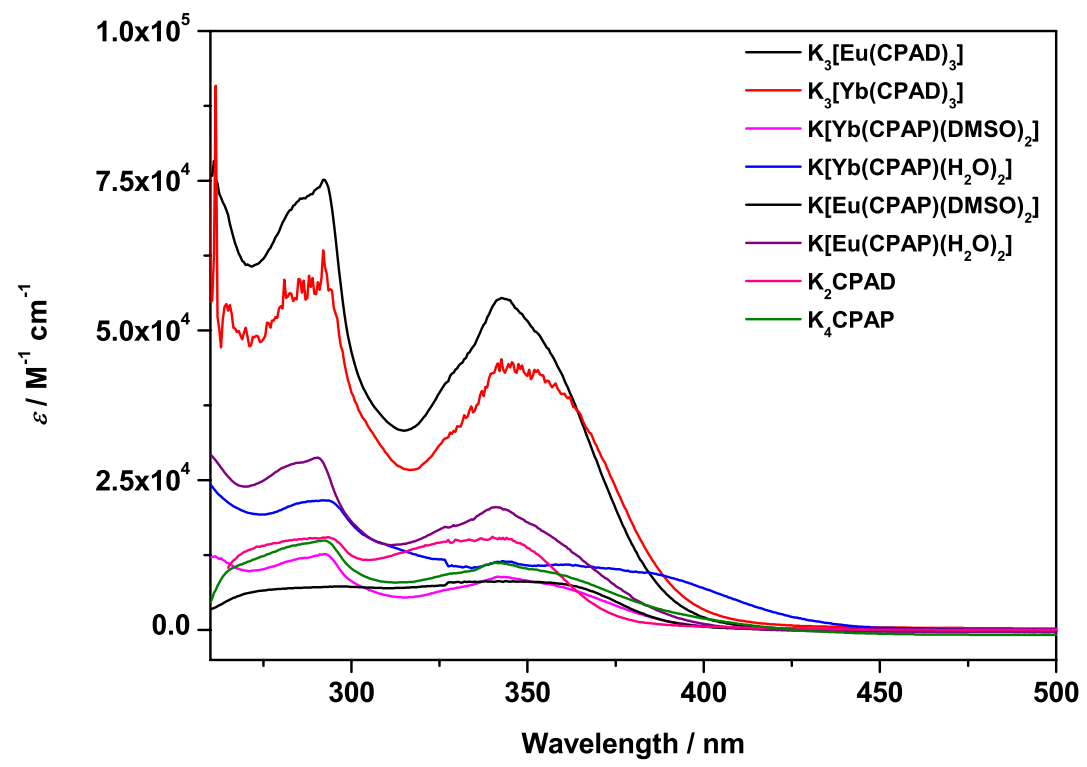

Figure S22. Absorption spectra of $\mathrm{K}_{2} \mathrm{CPAD}, \mathrm{K}_{4} \mathrm{CPAP}$, and their EuII and $\mathrm{Yb}$ 


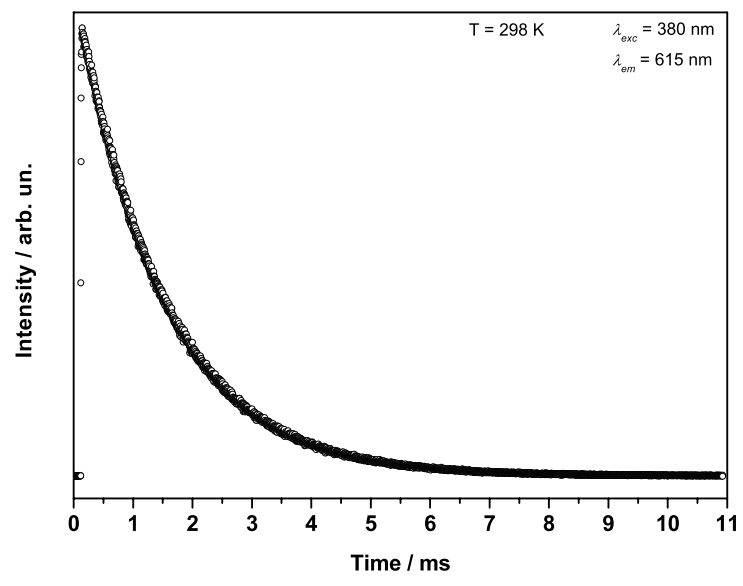

(a)

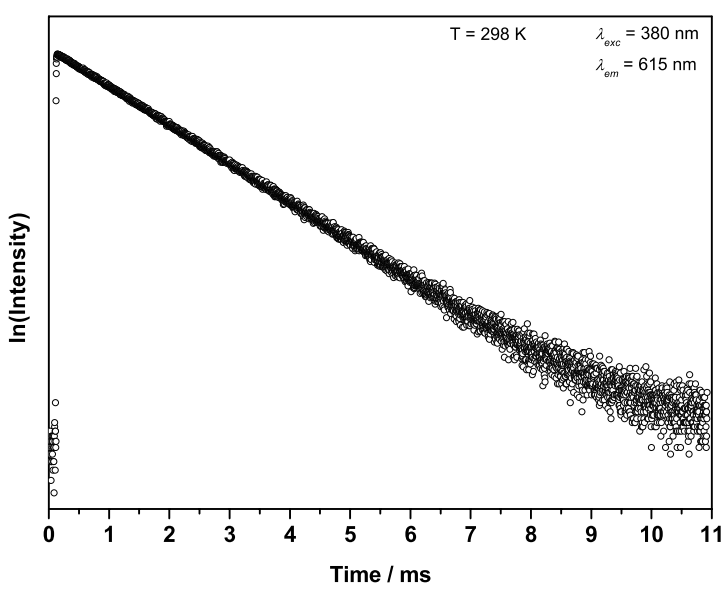

(b)

Figure S23. Emission lifetime decay curves of the complex $\mathrm{K}_{3}\left[\mathrm{Eu}(\mathrm{CPAD})_{3}\right]$ obtained in DMSO at $298 \mathrm{~K}$. (a) Exponential decay. (b) Linearization.

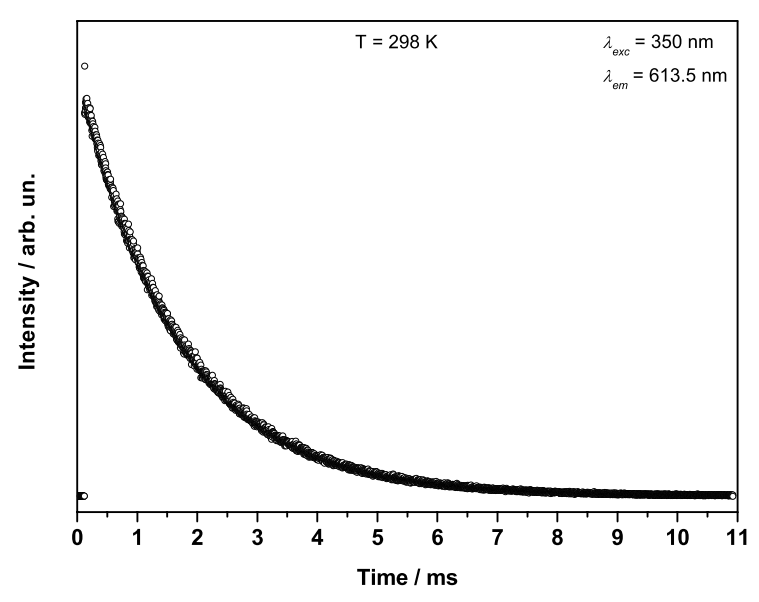

(a)

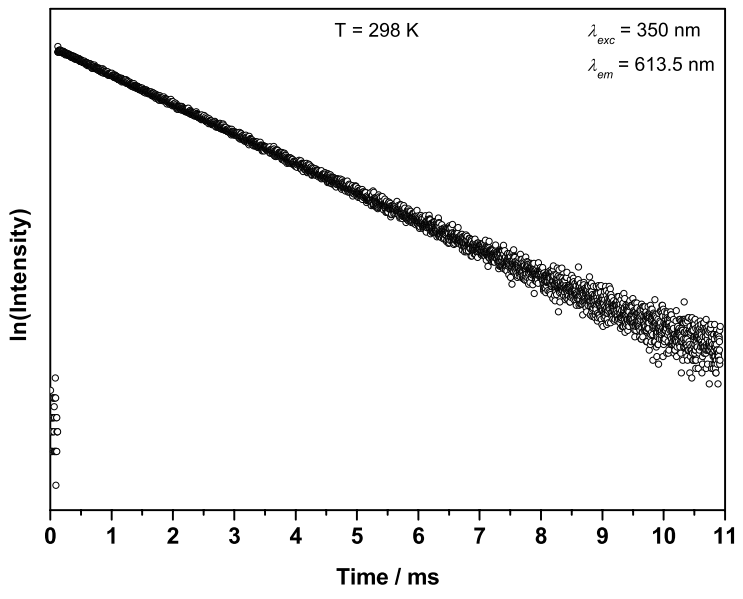

(b)

Figure S24. Emission lifetime decay curves of the complex K[Eu(CPAP)(DMSO)2] obtained in DMSO at 298 K. (a) Exponential decay. (b) Linearization. 


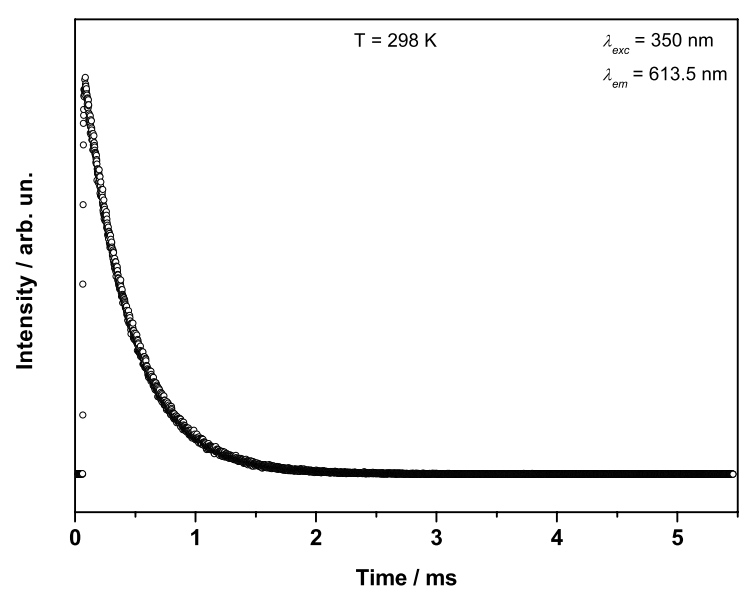

(a)

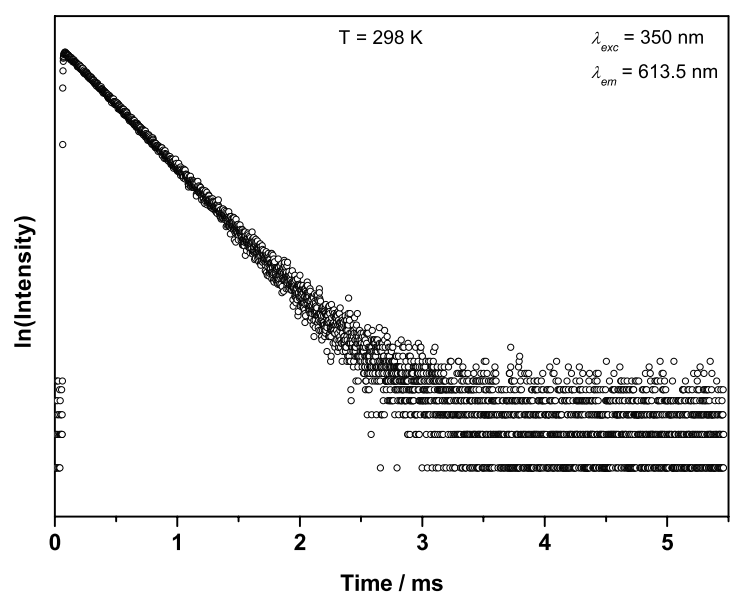

(b)

Figure S25. Emission lifetime decay curves of the complex $\mathrm{K}\left[\mathrm{Eu}(\mathrm{CPAP})\left(\mathrm{H}_{2} \mathrm{O}\right)_{2}\right]$ obtained in an aqueous TRIS/HCl buffered solution (10\% DMSO, pH 7.4) at 298 K. (a) Exponential decay. (b) Linearization.

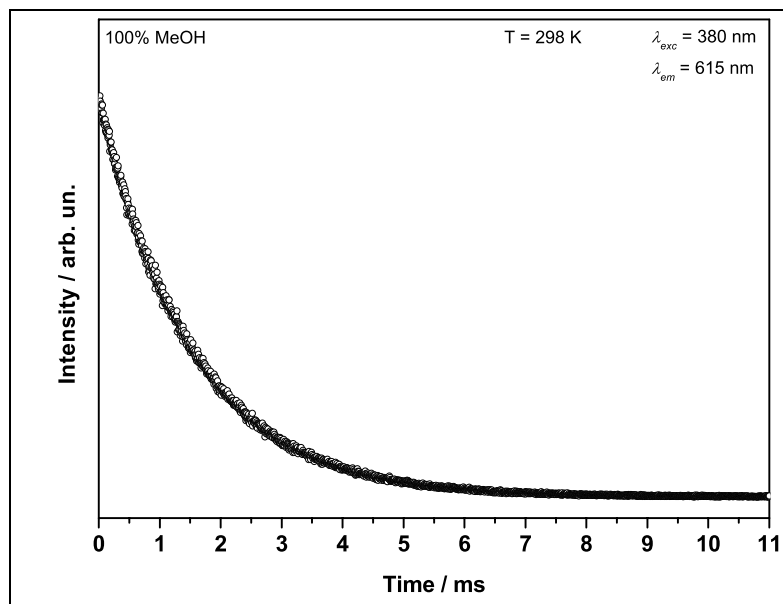

(a)

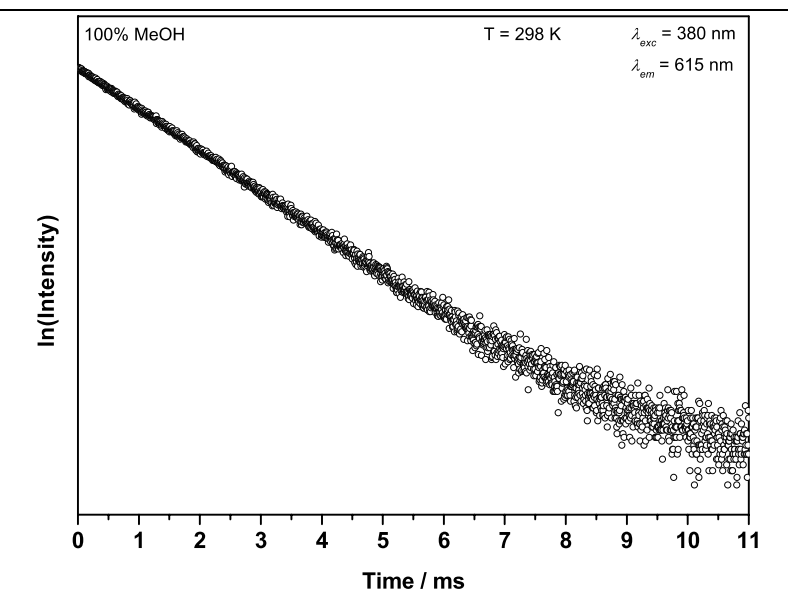

(b)

Figure S26. Emission lifetime decay curves of the complex $\mathrm{K}_{3}\left[\mathrm{Eu}(\mathrm{CPAD})_{3}\right]$ obtained in $\mathrm{MeOH}$ at $298 \mathrm{~K}$. (a) Exponential decay. (b) Linearization. 


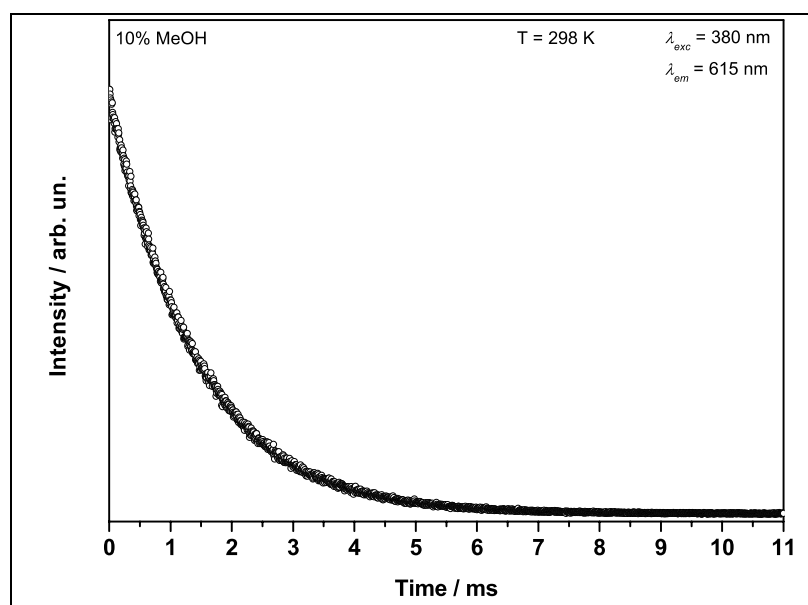

(a)

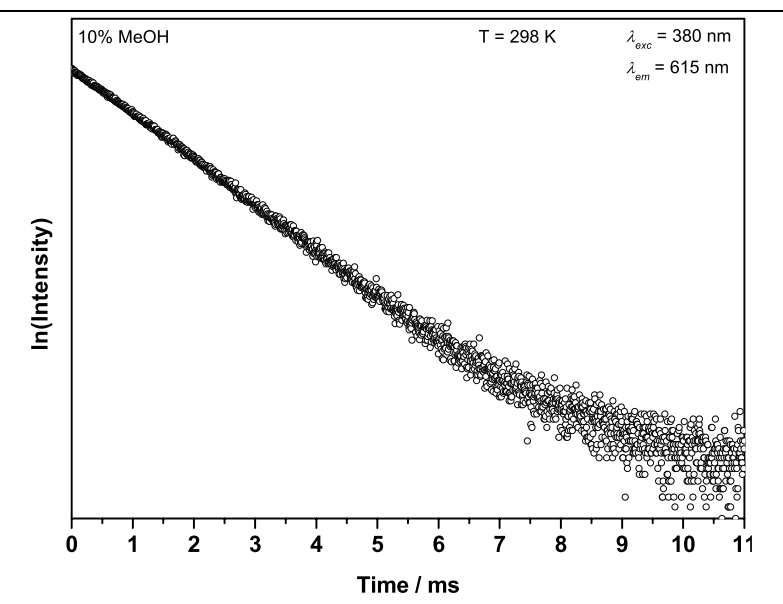

(b)

Figure S27. Emission lifetime decay curves of the complex $\mathrm{K}_{3}\left[\mathrm{Eu}(\mathrm{CPAD})_{3}\right]$ obtained in $10 \% \mathrm{MeOH}+90 \%$ glycerol at 298 K. (a) Exponential decay. (b) Linearization.

Table S1. Intrinsic emission efficiency $\left(\boldsymbol{\Phi}_{\boldsymbol{E} u}^{\boldsymbol{E u}}\right)$, quantum yield $\left(\boldsymbol{\Phi}_{\boldsymbol{L}}^{\boldsymbol{E u}}\right)$ of sensitized efficiency, sensitization efficiency ( $\left.\eta_{\text {sens }}\right)$, distance donor-acceptor $\left(R_{L}\right)$ and lifetime $(\tau)$ for the $\mathrm{Css}_{3}\left[\mathrm{Eu}(\mathrm{dpa})_{3}\right]$ (dpa $=$ dipicolinato) in DMSO. [complex] $=1 \mathrm{x} 10-4 \mathrm{M}$.

\begin{tabular}{|cccccc|}
\hline Complex & $\Phi_{E u}^{E u} / \%$ & $\Phi_{L}^{E u} / \%$ & $\eta_{\text {sens }} / \%$ & $R_{L} / \AA$ & $\tau / \mathrm{ms}$ \\
\hline $\mathrm{Cs}_{3}\left[\mathrm{Eu}(\mathrm{dpa})_{3}\right]$ & 85.2 & $64.6 \pm 4.0$ & 75.8 & 4.1496 & $2.549 \pm 0.013$ \\
\hline
\end{tabular}

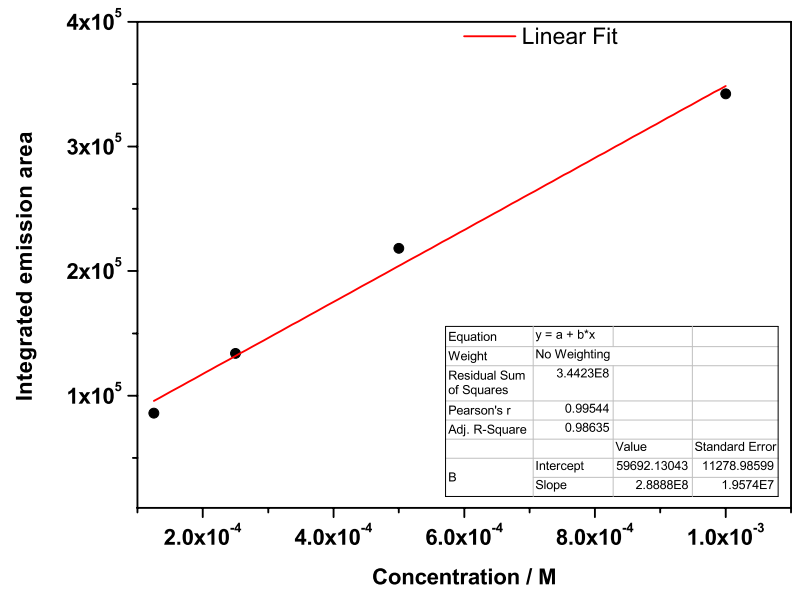

Figure S28. Plot of integrated emission area as a function of rhodamine concentration. $\lambda_{e x c}=750 \mathrm{~nm}$. 


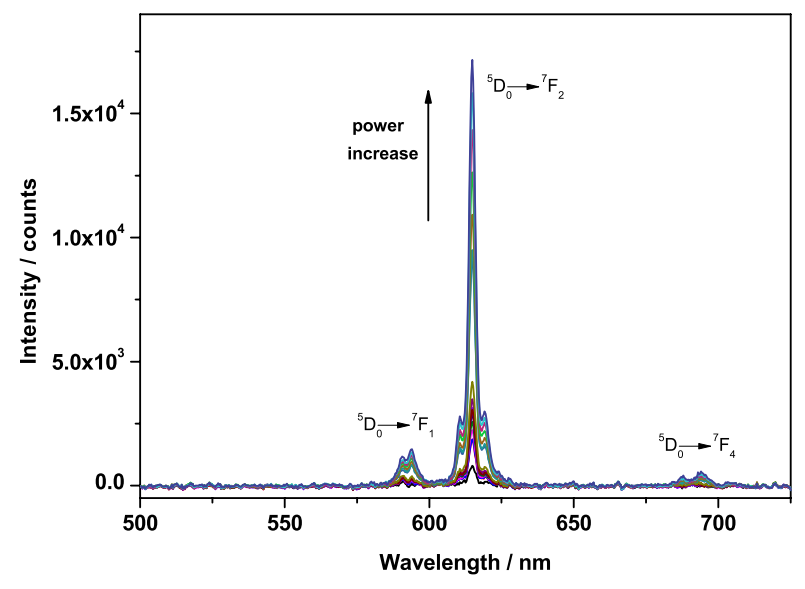

(a)

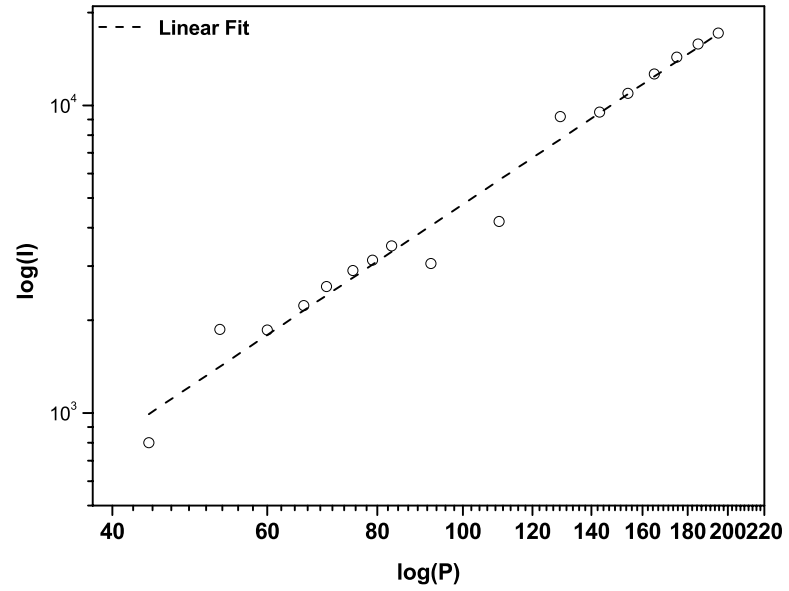

(b)

Figure S29. (a) Emission spectra of the complex $\mathrm{K}_{3}\left[\mathrm{Eu}(\mathrm{CPAD})_{3}\right]$ obtained at different laser powers. (b) Plot of $\log$ (I) as a function of $\log (\mathrm{P})$. Concentration $=1 \times 10-4 \mathrm{M}$ in DMSO.

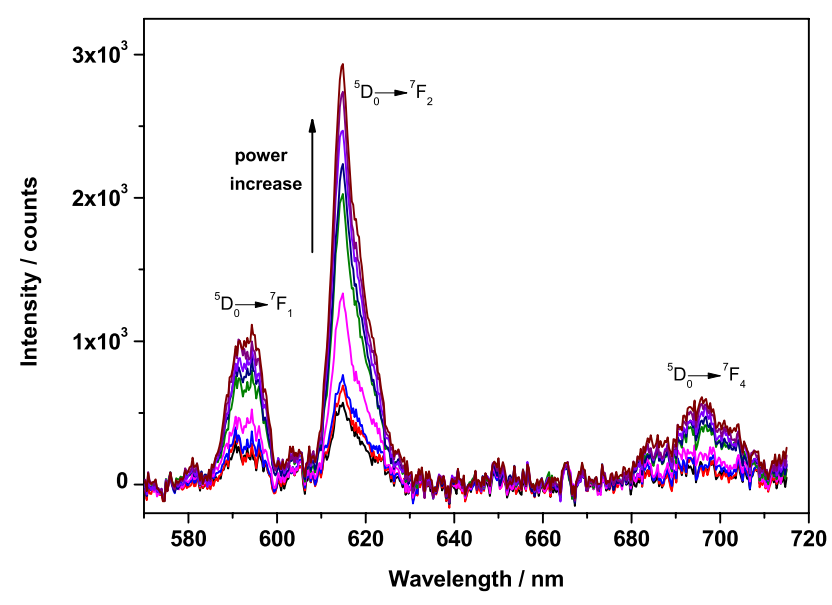

(a)

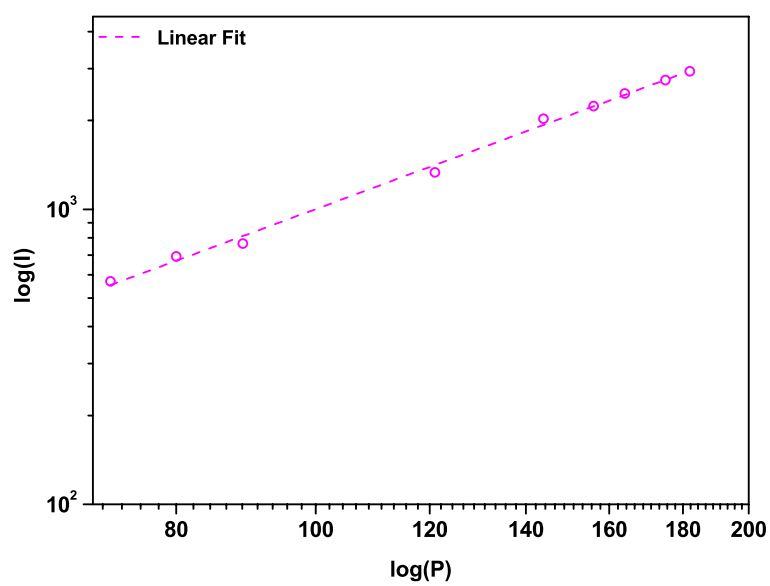

(b)

Figure S30. Emission spectra of the complex K[Eu(CPAP)(DMSO) 2$]$ obtained at different laser powers. (b) Plot of $\log (\mathrm{I})$ as a function of $\log (\mathrm{P})$. Concentration $=1 \times 10-4 \mathrm{M}$ in DMSO. 


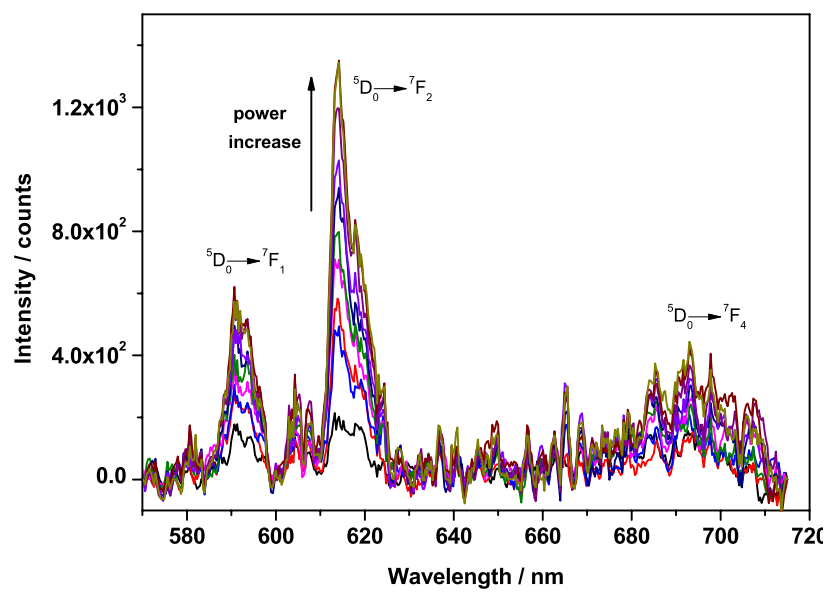

(a)

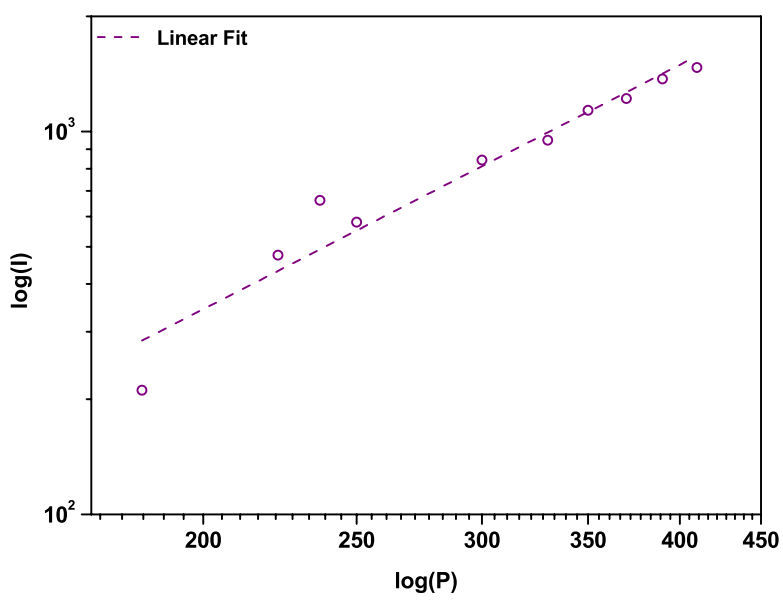

(b)

Figure S31. Emission spectra of the complex $\mathrm{K}\left[\mathrm{Eu}(\mathrm{CPAP})\left(\mathrm{H}_{2} \mathrm{O}\right)_{2}\right]$ obtained at different laser powers. (b) Plot of $\log (\mathrm{I})$ as a function of $\log (\mathrm{P})$. Concentration $=1 \times 10-4 \mathrm{M}$ in aqueous TRIS/HCl buffered solution $(10 \% \mathrm{DMSO}, \mathrm{pH}$ 7.4).

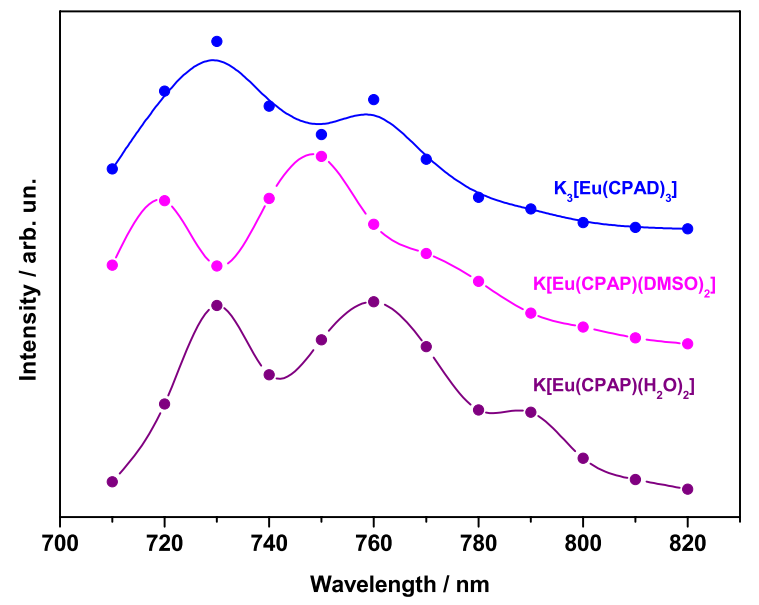

Figure S32. Two-photon excitation spectra of $\mathrm{K}_{3}\left[\mathrm{Eu}(\mathrm{CPAD})_{3}\right]$ (in DMSO - blue), $\mathrm{K}\left[\mathrm{Eu}(\mathrm{CPAP})(\mathrm{DMSO})_{2}\right]$ (in DMSO - pink) and $\mathrm{K}\left[\mathrm{Eu}(\mathrm{CPAP})\left(\mathrm{H}_{2} \mathrm{O}\right)_{2}\right]$ (in aqueous TRIS/HCl buffered solution 10\% DMSO, $\mathrm{pH} \sim 7.4$ - purple). $[$ complex $]=1 \times 10-4 \mathrm{M}$.

Table S2. Slopes for the plots of $\log (\mathrm{I})$ as a function of $\log (\mathrm{P})$ and corresponding values of $R 2$.

\begin{tabular}{|cccc|}
\hline Complex & Solvent & Slope & $R_{2}$ \\
\hline $\mathrm{K}_{3}\left[\mathrm{Eu}(\mathrm{CPAD})_{3}\right]$ & DMSO & $1.95 \pm 0.11$ & 0.975 \\
\hline $\mathrm{K}\left[\mathrm{Eu}(\mathrm{CPAP})(\mathrm{DMSO})_{2}\right]$ & DMSO & $1.84 \pm 0.04$ & 0.996 \\
\hline $\mathrm{K}\left[\mathrm{Eu}(\mathrm{CPAP})\left(\mathrm{H}_{2} \mathrm{O}\right)_{2}\right]$ & Water:DMSO & $2.12 \pm 0.03$ & 0.914 \\
\hline
\end{tabular}




\section{References}

1. $\quad$ Bassett, J.; Denney, R. C.; Jeffery, G. H.; Mendham, J., Vogel's Textbook of Quantitative Inorganic Analysis. 4th ed. ed.; Longman Group: London, 1978.

2. Takalo, H.; Pasanen, P.; Kankare, J., Synthesis of 4-(Phenylethynyl)-2,6-bis N,N-bis-(carboxymethyl)aminomethyl pyridine. Acta Chemica Scandinavica Ser. B 1988, 42, 373-377.

3. Gilday, L. C.; Lang, T.; Caballero, A.; Costa, P. J.; Felix, V.; Beer, P. D., A Catenane Assembled through a Single ChargeAssisted Halogen Bond. Angew. Chem. Int. Ed. 2013, 52, 4356-4360.

4. Di Pietro, S.; Gautier, N.; Imbert, D.; Pecaut, J.; Mazzanti, M., Versatile Pyridine-2,6-bis-tetrazolate Scaffolds for the Formation of Highly Luminescent Lanthanide Complexes. Dalton Trans. 2016, 45, 3429-3442.

5. Joseph, A.; Subramanian, S.; Ramamurthy, P. C.; Sampath, S.; Kumar, R. V.; Schwandt, C., Iminodiacetic Acid Functionalized Polypyrrole Modified Electrode as $\mathrm{Pb}(\mathrm{II})$ Sensor: Synthesis and DPASV Studies. Electrochim. Acta 2014, 137, 557563.

6. Caille, F.; Buron, F.; Toth, E.; Suzenet, F., Efficient Access to C1-and C3-Functionalized Isoquinolines: Towards Potential Lanthanide Ligands. Eur. J. Org. Chem. 2011, 2120-2127.

7. Supkowski, R. M.; Horrocks, W. D., On the Determination of the Number of Water Molecules, q, Coordinated to Europium(III) Ions in Solution From Luminescence Decay Lifetimes. Inorg. Chim. Acta 2002, 340, 44-48.

8. $\quad$ Crosby, G. A.; Whan, R. E.; Alire, R. M., Intramolecular Energy Transfer in Rare Earth Chelates. Role of the Triplet State. J. Chem. Phys. 1961, 34, 743-748.

9. Ding, J.; Wang, Q.; Zhao, L.; Ma, D.; Wang, L.; Jing, X.; Wang, F., Design of Star-shaped Molecular Architectures Based on Carbazole and Phosphine Oxide Moieties: Towards Amorphous Bipolar Hosts With High Triplet Energy for Efficient Blue Electrophosphorescent Devices. J. Mater. Chem. 2010, 20, 8126-8133.

10. Vicente, J.; Gil-Rubio, J.; Zhou, G.; Bolink, H. J.; Arias-Pardilla, J., Synthesis and Luminescence of Poly(phenylacetylene)s with Pendant Iridium Complexes and Carbazole Groups. J. Polym. Sci. A 2010, 48, 3744-3757.

11. Picot, A.; Feuvrie, C.; Barsu, C.; Malvolti, F.; Le Guennic, B.; Le Bozec, H.; Andraud, C.; Toupet, L.; Maury, O., Synthesis, Structures, Optical Properties, and TD-DFT Studies of Donor- $\pi$-conjugated Dipicolinic Acid/ester/amide Ligands. Tetrahedron 2008, 64, 399-411.

12. Tsvirko, M. P.; Meshkova, S. B.; Venchikov, V. Y.; Topilova, Z. M.; Bol'shoi, D. V., Determination of Contributions of Various Molecular Groups to Nonradiative Deactivation of Electronic Excitation Energy in Beta-diketonate Complexes of Ytterbium(III). Opt. Spectrosc. 2001, 90, 669-673.

13. D'Aléo, A.; Andraud, C.; Maury, O., Two-photon Absorption of Lanthanide Complexes: from Fundamental Aspects to Biphotonic Imaging Applications. In Luminescence of Lanthanide Ions in Coordination Compounds and Nanomaterials, John Wiley \& Sons Ltd: Chichester, 2014; pp 197-230.

14. Makarov, N. S.; Drobizhev, M.; Rebane, A., Two-photon Absorption Standards in the 550-1600 nm Excitation Wavelength Range. Opt. Express 2008, 16, 4029-4047. 